\title{
Adriana FelD*
}

\author{
POLÍTICA EXTERIOR Y REDES PÚBLICO-PRIVADAS \\ EN LA ORGANIZACIÓN DE LAS RELACIONES TECNOCIENTÍFICAS \\ DE Estados Unidos CON AmÉRICA Latina: \\ UNA APROXIMACIÓN \\ a Partir del Programa de Investigación y Cultivo de Hevea \\ $(1920-1953)^{1}$
}

\begin{abstract}
RESUMEN
En este artículo abordo el modo en que Estados Unidos organizó sus relaciones tecnocientíficas con América Latina durante la Segunda Guerra Mundial y la inmediata posguerra. Para ello, en este artículo analizo el caso del programa regional de investigación y desarrollo del cultivo de Hevea (la principal fuente de caucho), implementado por el Departamento de Agricultura de Estados Unidos (USDA) en América Latina. La investigación se asienta en diversas fuentes, como la revista Agriculture in the Americas, documentos del USDA y artículos de expertos estadounidenses que participaron del programa. En diálogo con algunas contribuciones del campo de los estudios socio-históricos de la ciencia referidos a las relaciones Norte-Sur en diferentes etapas, exploro la especificidad de este periodo, poniendo el foco en los dispositivos y arreglos institucionales que organizaron las relaciones tecnocientíficas interamericanas, las implicancias que tuvieron en términos de la distribución del trabajo y la información científica Norte-Sur, los principales interlocutores latinoamericanos de las agencias estadounidenses y el tipo de conocimiento (científico o no) involucrado en el programa.
\end{abstract}

Palabras claves: Estados Unidos, América Latina, siglo XX, Norte-Sur, relaciones tecnocientíficas, agricultura, Hevea.

\section{Abstract}

In this article I address the way in which the United States organized the techno-scientific relations with Latin America during World War II and the immediate postwar period. To this end, I analyze the case of the regional research and development program for the cultivation of Hevea (the main source of rubber), implemented by the United States Department of Agriculture (USDA) in Latin America. The research is based on various sources, such as the journal Agriculture in the Americas, USDA documents and articles

\footnotetext{
* Doctora en Ciencias Sociales, Universidad de Buenos Aires. Investigadora del Conicet en el Centro de Ciencia, Tecnología y Sociedad de la Universidad Maimónides (Argentina). Correo electrónico: feldri75@yahoo.com.mx

${ }^{1}$ La Hevea es un árbol nativo del Amazonas, del que se extrae el látex para la producción de caucho.
} 
published by American experts who participated in the program. In dialogue with some contributions from the field of socio-historical studies of science regarding North-South relations at different historical stages. I specifically explore this period, focusing on the devices and institutional arrangements that organized the inter-American techno-scientific relations, the implications they had in terms of the distribution of North-South scientific work and information, the main Latin American representatives of the American agencies and the type of knowledge (scientific or not) involved in the program.

Keywords: United States, Latin America, twentieth century, North-South, techno-scientific relations, agriculture, Hevea.

Recibido: Enero 2021.

Aceptado: Julio 2021.

\section{INTRODUCCIÓN}

Desde mediados del siglo XIX, luego de que Charles Goodyear descubriera el proceso de vulcanización del caucho, se incrementaron las aplicaciones de esta materia prima, extraída mayormente de árboles silvestres de Hevea del Amazonas: máquinas industriales, bombas para minas, ferrocarriles, cables de telégrafo, automóviles, bicicletas e insumos para la industria eléctrica produjeron un incremento sin precedentes de la demanda, que llegó a sextuplicarse entre 1890 y $1910^{2}$. Por entonces, cuando Estados Unidos emergía como potencia industrial y Brasil producía la mitad de la oferta mundial de caucho basado en la extracción de látex de árboles silvestres ${ }^{3}$, Gran Bretaña y Holanda comenzaron a construir su propio monopolio, instalando plantaciones de Hevea brasiliensis traído del Amazonas en sus colonias asiáticas ${ }^{4}$. A principios de la década de 1920 el mercado brasileño había colapsado y las plantaciones británicas controlaban dos tercios de la producción mundial de caucho. Ante la caída de los precios, luego de la Primera Guerra Mundial, las autoridades británicas establecieron una serie de medidas para

\footnotetext{
${ }^{2}$ Warren Dean, Brazil and the Struggle for Rubber. A Study in Environmental History, Cambridge, Cambridge University Press, 1987, p. 32.

${ }^{3}$ Wade Davis, El rio: exploraciones y descubrimientos en la selva amazónica, Bogotá, D.C, Ministerio de Cultura-Biblioteca Nacional de Colombia, 2017, p. 568. Sobre la organización del sistema de explotación y comercialización del caucho en Brasil en la segunda mitad del siglo XIX y las primeras décadas del siglo XX, véase Bárbara Weinstein, The Amazon Rubber Boom 1850-1920, Stanford, Stanford University Press, 1983.

${ }^{4}$ En 1870 ya se sabía que el caucho podía extraerse de unas cien especies de plantas diferentes. Los ingleses dependían de la Ficus elastica, una planta nativa de Asia, que intentaron, sin éxito, sembrar en plantaciones. En 1876, los Royal Kew Gardens y la India Office británicos le ofrecieron al inglés Henry Wickham, un recolector de plantas por entonces instalado en Santarém (Brasil), pagarle diez libras por cada mil semillas de Hevea. Wickham les envió setenta mil semillas y, de aquellas que germinaron, mil novecientos especímenes fueron enviados a los Paradeniya Gardens en Ceilán y veintidós a Singapur. Ese fue el origen de las primeras plantaciones establecidas en las colonias británicas, holandesas y francesas a partir de 1900. Davis, op. cit., pp. 560-562; Lucile H. Brockway, "Science and Colonial Expansion: The Role of the British Royal Botanic Gardens", in American Ethnologist, vol. 6, No. 3, 1979, pp. 449-465. Disponible en https://anthrosource. onlinelibrary.wiley.com/doi/epdf/10.1525/ae.1979.6.3.02a00030 [fecha de consulta: 3 de diciembre de 2020]
} 
restringir la producción y subir los precios (lo que se conoce como Plan Stevenson) ${ }^{5}$. En ese marco, en Estados Unidos se iniciaron esfuerzos sistemáticos, tanto públicos como privados, para identificar plantas proveedoras de caucho en su territorio nacional y en América Latina a partir de las cuales pudieran desarrollarse cultivos ${ }^{6}$.

Sin embargo, en vísperas de la Segunda Guerra Mundial, ninguno de esos proyectos había obtenido resultados que garantizaran una fuente de abastecimiento segura. La situación era apremiante: el centro de gravitación de la producción de caucho se había desplazado al Sudeste Asiático, que producía el 97 \% del caucho mundial, del cual Estados Unidos consumía el $60 \%$. Para hacer frente al incierto escenario, las autoridades estadounidenses discutieron cuatro líneas de acción posibles: a) acopiar caucho natural importado del Sudeste Asiático y de América Latina; b) apostar al desarrollo del caucho sintético; c) experimentar con el cultivo de plantas domésticas de caucho; d) promover el cultivo de Hevea en América Latina ${ }^{8}$. Durante la guerra, y con mayor ímpetu aún luego del ataque a Pearl Harbor, estas cuatro líneas se desplegaron en forma paralela. En particular, la articulación del complejo estatal-industrial-académico en torno a los programas de caucho sintético y de cultivos domésticos, que movilizaron capital, recursos humanos, infraestructura y tierras a una escala sin precedentes, permite equipararlos, por su magnitud, con el Proyecto Manhattan.

Aunque, en términos comparativos, la inversión del gobierno estadounidense en el programa de cultivo de Hevea en América Latina no fue tan significativa ${ }^{10}$, el complemento provisto por empresas estadounidenses y gobiernos latinoamericanos, así como la movilización de recursos humanos, genéticos y de tierras, permite enmarcarlo en este inmenso despliegue que significó la "batalla por el caucho". Contando en sus inicios con la colaboración de trece países de la región (reducidos a ocho al finalizar la contienda) y gestionado por el Bureau of Plant Industry (BPI) del United States Department of Agriculture (USDA), el programa se prolongó más allá de la emergencia bélica y siguió hasta fines de $1953^{11}$.

${ }^{5}$ Richard P. Tucker, Insatiable Appetite: The United States and the Ecological Degradation of the Tropical World, Berkeley/Los Angeles/London, University of California Press, 2000, p. 248.

${ }^{6}$ Mark Finlay, Growing American Rubber: Strategic Plants and the Politics of National Security, New Brunswick, New Jersey, Rutgers University Press, 2009, pp. 3-7.

${ }^{7}$ John J. Blandin, "Why Rubber is Coming Home", in Agriculture in the Americas, Washington D.C., May 1941, p. 10. Disponible en https://hdl.handle.net/2027/umn.31951d00045071j?urlappend=\%3Bseq=73 [fecha de consulta: 20 de mayo de 2020].

${ }^{8}$ Finlay, op. cit.

${ }^{9}$ Sobre el programa de cultivo de plantas domésticas proveedoras de caucho véase Finlay, op. cit. Acerca del programa de investigación y desarrollo de caucho sintético pueden consultarse Peter J. T. Morris, "Synthetic Rubber: Autarky and War", in S. T. I. Mossman \& Peter J. T. Morris (eds.), The Development of Plastics, Cambridge, The Royal Society of Chemistry, 1994, pp. 54-69; Vernon Herbert \& Attilio Bisio, Synthetic Rubber: The Project That Had to Succeed, Westport, Greenwood Press, 1985.

${ }^{10}$ Entre 1942 y 1952, el gobierno estadounidense había invertido unos USD 40000000 en el programa de caucho sintético, mientras que el de cultivo de Hevea había insumido apenas USD 2800000 en los catorce años que duró. Davis, op. cit., pp. 665-666 y 668.

${ }^{11}$ Aunque en 1945 las plantas petroquímicas estadounidenses producían el $85 \%$ del caucho consumido en Estados Unidos, pronto se puso en evidencia que el caucho natural tenía amplias ventajas en términos de precio, flexibilidad, durabilidad y resistencia y resultaba irreemplazable para algunos productos. Eso explica, en parte, la continuidad del proyecto en América Latina. Davis, op. cit., p. 665; Ernest P. Imle, "Hevea Rubber - Past and Future", in Economic Botany, vol. 32, No. 3, New York, 1979, pp. 264-277. 
Este artículo reconstruye la historia de ese programa, que fue uno de los tantos "proyectos colaborativos científicos y técnicos" -según la denominación utilizada en documentos públicos- implementados por Estados Unidos en América Latina desde el inicio de la Segunda Guerra Mundial. El caso en sí mismo es interesante por el carácter estratégico y la circulación transnacional de la Hevea, que arrastró consigo relaciones diplomáticas, conocimiento científico o modelos de organización de la producción agrícola. Pero además permite pensar las relaciones tecnocientíficas interamericanas en este periodo en particular, que suele considerarse un punto de inflexión a partir del cual la "cooperación científica" se incorporó como una rama crucial de la política exterior estadounidense ${ }^{12}$. En buena medida, la inquietud que motivó el estudio de este caso fue indagar el modo en que Estados Unidos organizó la "cooperación científica" con América Latina durante la Segunda Guerra Mundial y la inmediata posguerra.

Desde luego, cabe señalar que el concepto de "cooperación científica" es bastante ambiguo y polisémico. Jacques Gaillard, en uno de los pocos trabajos que ha propuesto una periodización de largo plazo de los programas de "cooperación científica" NorteSur, ha llamado la atención sobre las dificultades para conceptualizar esos programas, pues tanto documentos públicos como estudios académicos han empleado, de modo intercambiable y fluctuante en el tiempo, términos muy diferentes, como "cooperación científica" o "asistencia técnica", para hacer referencia a modos de organización o prácticas distintas ${ }^{13}$. En ese sentido, lo primero a destacar es que la cooperación científica puede estar mediada por un amplio abanico de arreglos institucionales y organizacionales, que va desde programas diseñados por instituciones filantrópicas, instituciones públicas nacionales (en este caso de Estados Unidos) o regionales (como los más recientes programas marco de la Unión Europea) hasta proyectos emanados de vínculos informales entre científicos. En segundo lugar, los programas diseñados por organismos públicos o privados pueden tener múltiples interlocutores, ya sean los gobiernos, el sector productivo (empresas o productores) o las élites científicas. En tercer lugar, el contenido "científico" o "técnico" de la relación no involucra necesariamente -o en forma exclusiva- proyectos de investigación conjunta, sino que puede implicar investigación en territorio extranjero con participación subordinada o marginal de científicos locales, programas de formación de recursos humanos, procesos de transferencia de tecnología, de know-how técnico, de gestión o de organización y diversas combinaciones de todas estas líneas de acción. En relación con esto último, podemos advertir que el concepto de "cooperación científica" -o el uso nativo del término "proyectos colaborativos'- tiende a opacar las asimetrías sobre las que se asientan, y a su vez expresan, las relaciones tecnocientíficas Norte-Sur. Aunque el término utilizado en la inmediata posguerra -'asistencia técnica'- da cuenta de la posición desigual que ocupan los países, nos dice poco acerca de la organización de las relaciones entre los científicos, técnicos o expertos. En otro trabajo, que también propuso una periodización de largo plazo de las relaciones

\footnotetext{
${ }^{12}$ Clark A. Miller, “'An effective instrument of peace' Scientific cooperation as an instrument of U.S. foreign policy, 1938-1950”, in Osiris, vol. 21, Chicago, 2006, pp. 133-160.

${ }_{13}$ Jacques Gaillard, La Coopération Scientifique et Technique Avec les Pays du Sud. Peut-on Partager la Science?, Paris, Karthala, 1999.
} 
tecnocientíficas entre contextos periféricos y contextos desarrollados (aunque desde una perspectiva diferente), Pablo Kreimer acuñó el concepto de "integración subordinada", que puede echar luz sobre este último aspecto ${ }^{14}$.

Tomando en consideración estas distinciones, el análisis del caso propuesto se organizará en torno a un conjunto de interrogantes que también pueden servir para analizar, en forma comparada, otros periodos. ¿A través de qué dispositivos y arreglos institucionales se organizaron esas relaciones? ¿Qué implicancias tuvieron en términos de la distribución del trabajo y la información científica Norte-Sur? ¿Quiénes eran los principales interlocutores de las agencias estadounidenses? y ¿qué tipo de conocimiento (científico o no) estuvo involucrado en esos programas?

Recientemente, los trabajos de Nicolás Cuvi referidos al programa de cultivos estratégicos y complementarios con la agricultura estadounidense desarrollados por el USDA en América Latina han ofrecido evidencia empírica y claves interpretativas muy valiosas para comprender las relaciones tecnocientíficas de este periodo y enmarcar el programa de Hevea ${ }^{15}$. Lejos de evocar el concepto de "cooperación científica", el autor sitúa dichos programas en la intersección entre ciencia e imperialismo, un cruce casi ineludible en este tipo de programas ${ }^{16}$. En este trabajo recupero sus contribuciones, haciendo hincapié en dos elementos que pueden ser relevantes para caracterizar esa intersección. Por un lado, la conformación y reconfiguración de redes público-privadas en torno a la investigación y cultivo de Hevea en América Latina. Para eso, aunque el periodo que me interesa analizar es el que transcurre durante la guerra y la inmediata posguerra, reseño los antecedentes del programa en busca de las configuraciones específicas que asumió esa articulación antes y después del conflicto armado. Por otro lado, también se pondrá de manifiesto que el contacto de las élites científicas y económicas estadounidenses con ideas, prácticas, técnicas, conocimientos y modelos de organización desplegados por las metrópolis europeas en sus colonias fue un insumo fundamental para el programa. De hecho, desde principios del siglo XX el tópico de la complementariedad productiva entre metrópolis y colonias, así como el establecimiento de estaciones agrícolas de investigación en las diferentes posesiones, fue un rasgo central de la polí-

\footnotetext{
${ }^{14}$ Pablo Kreimer, “¿Dependientes o integrados? La ciencia latinoamericana y la división internacional del trabajo", en Nómadas-Clacso, n. ${ }^{\circ} 24$, Bogotá, 2006, pp. 199-212.

${ }^{15}$ Nicolás Cuvi, "Las semillas del imperialismo agrícola estadounidense en el Ecuador", en Procesos. Revista Ecuatoriana de Historia, n. ${ }^{\circ}$ 30, Quito, 2009, pp. 69-98; Nicolás Cuvi, “'Dejen que el diablo haga lo demás': la promoción de productos complementarios en América Latina durante la década de 1940", en Historia Crítica, n. ${ }^{44}$, Bogotá, 2011, pp. 158-181; Nicolás Cuvi, "The Cinchona Program (1940-1945): Science and Imperialism", en Dynamis, vol. 31, n. ${ }^{\circ}$ 1, Granada, 2011, pp. 183-206; Nicolás Cuvi, "Mapas confidenciales y mapas de planificación: imágenes estadounidenses del territorio latinoamericano en la década de 1940”, en Apuntes, vol. 26, n. ${ }^{1}$ 1, Lima, 2013, pp. 26-45; Nicolás Cuvi, "Expertos, agrobraceros y resistencias durante los inicios de la larga revolución verde en los Andes", en Historia Ambiental Latinoamericana y Caribeña (HALAC) Revista de la Solcha, vol. 10, n. ${ }^{\circ} 3$, Anápolis, 2020, pp. 227-264. Disponible en www.halacsolcha.org/index.php/halac/article/view/440/440 [fecha de consulta: 5 de septiembre de 2021].

${ }^{16}$ Para una discusión historiográfica sobre la relación ciencia e imperialismo con especial referencia al papel de Estados Unidos, véase Camilo Quintero Toro, “¿En qué anda la historia de la ciencia y el imperialismo? Saberes locales, dinámicas coloniales y el papel de los Estados Unidos en la ciencia del siglo XX”, en Historia Crítica, n. ${ }^{\circ}$ 31, Bogotá, 2006, pp. 151-172. Disponible en www.redalyc.org/articulo.oa?id=81103107 [fecha de consulta: 2 de agosto de 2021].
} 
tica colonial de países como Inglaterra y Francia ${ }^{17}$. Por último, indago el modo en que científicos y expertos latinoamericanos se integraron en programas de investigación y "redes de conocimiento" diseñadas por expertos estadounidenses ${ }^{18}$.

El artículo está organizado del siguiente modo: la primera sección reseña el marco político-institucional estadounidense en el que se insertó el programa de cultivo de Hevea y recorre sus antecedentes. La segunda, aborda en forma más específica el contenido, implementación y evolución del programa, prestando particular atención al tipo de interlocutores privilegiados y al papel asignado a los científicos o expertos del Sur. Por último, las conclusiones presentan un análisis del caso descrito, tomando como eje las distinciones conceptuales y los interrogantes planteados, en diálogo con algunos aportes de la literatura sobre relaciones tecnocientíficas Norte-Sur. En todo este recorrido, me concentraré en el modo en que actores e instituciones estadounidenses concibieron, diseñaron e implementaron las relaciones tecnocientíficas con América Latina, dejando provisoriamente en suspenso el contexto y la agencia de actores e instituciones latinoamericanas. Sin dudas, la historiografía de la ciencia sugiere enfoques analíticos y marcos conceptuales interesantes para abordar este último aspecto, que serán objeto de futuras investigaciones ${ }^{19}$.

${ }^{17}$ Christophe Bonneuil, "Crafting and Disciplining the Tropics: Plant Science in the French Colonies", in John Krige \& Dominique Pestre (eds.), Science in the Twentieth Century, Amsterdam, Harwood Academic, 1997, pp. 77-96; Michael Worboys, "British Colonial Science Policy, 1918-1939", in Patrick Petitjean (ed.), Les Sciences Coloniales: Figures and Institutions, Paris, ORSTOM, 1996, pp. 99-112.

${ }^{18}$ El clásico libro de Edward Berman ha mostrado la estrecha articulación entre actores e instituciones públicas y privadas en el diseño de la política exterior estadounidense a partir de la Segunda Guerra Mundial, poniendo el foco en el papel de las principales fundaciones filantrópicas. Más recientemente, en una línea similar, Inderjeet Parmar estudió el papel de dichas fundaciones en el proceso de construcción de la hegemonía estadounidense, tejida en "redes de conocimiento" integradas por las élites económicas, políticas e intelectuales, que se extendieron hacia diversos países. Aunque estos trabajos se han concentrado en el papel de las instituciones filantrópicas y en las ciencias sociales, sus propuestas resultan sugerentes para el caso aquí analizado. Edward Berman, The Influence of the Carnegie, Ford, and Rockefeller Foundations on American Foreign Policy: The Ideology of Philanthropy, Albany, State University of New York Press, 1984; Inderjeet Parmar, Foundations of the American Century: The Ford, Carnegie, and Rockefeller Foundations in the Rise of American Power, New York, Columbia University Press, 2012.

${ }^{19}$ Desde la década de 1990, tanto la historia cultural como la historia de la ciencia, aplicadas a las relaciones interamericanas, han propuesto nuevos abordajes que pusieron el foco en los procesos de colaboración, resistencia, intercambio, negociación, uso o resignificación que tienen lugar en lo que Mary Louise Pratt denominó "zonas de contacto". En ese marco, los estudios sobre los programas de las fundaciones estadounidenses para el desarrollo de diversas disciplinas de las ciencias naturales (fisiología, genética y agricultura) en América Latina (entre los que se destacan los aportes de Marcos Cueto y Hebe Vessuri) comenzaron a explorar los territorios de recepción de la asistencia estadounidense, la interacción con actores locales y la especificidad de los programas implementados a la luz de las características sociales, políticas, culturales y académicas del país receptor. En las últimas décadas, la historia de la ciencia ha dado un paso más en la complejización de las relaciones tecnocientíficas Norte-Sur, proponiendo enfoques que den cuenta de los procesos de coconstrucción (Norte-Sur) de hegemonía a través de la ciencia (como sugiere Alexis de Greiff) y de la participación del "Sur", de actores subalternos e intermediarios en los "espacios de circulación" y reconfiguración de conocimientos donde se coconstruye la ciencia. En esta última línea, se destacan, por ejemplo, los trabajos de Mauricio Nieto Olarte y Gabriela Soto Laveaga. Mary Louis Pratt, Ojos imperiales. Literatura de viaje y transculturación, Bernal, Universidad Nacional de Quilmes, 1997; Marcos Cueto (ed.), Missionaries of science. The Rockefeller Foundation in Latin America, Bloomington \& Indiana, Indiana University Press, 1994; Hebe Vessuri, "Foreign scientists, the Rockefeller foundation and the origins of agricultural science in Venezuela", in Minerva, vol. 32, No. 3, Bielefeld, 1994, pp. 267-296; Hebe Vessuri, "Scientific Cooperation among Unequal Partners: the StraitJacket of the Human Resource Base", in Jacques Gaillard (ed.), Coopérations Scientifiques Internationales, 


\section{LAS REDES PÚBLICO-PRIVADAS}

EN LA POLÍTICA EXTERIOR ESTADOUNIDENSE

Desde fines del siglo XIX, la ciencia ha acompañado la expansión de las corporaciones estadounidenses en América Latina. Como señala Camilo Quintero Toro, "a medida que Estados Unidos reemplazaba lentamente a Europa como principal fuerza política y económica en diferentes países latinoamericanos" a través de la creciente presencia de enclaves y corporaciones, diversas instituciones científicas como la National Geographic Society, el Museo Americano de Historia Natural de Nueva York o la Smithsonian Institution, comenzaron a mirar hacia América Latina y a realizar expediciones ${ }^{20}$. Sin embargo, como indica Emily Rosenberg, en la década de 1930, con la Política de Buena Vecindad, se puso en marcha una nueva modalidad de expansión comercial y cultural, a partir de la cual el Estado intervino de un modo más directo, marcando la transición desde un "estado cooperativo" con corporaciones e instituciones privadas hacia un "estado regulatorio"21.

En línea con el enfoque de Emily Rosenberg, desde la década de 1980, los estudios sobre la política exterior estadounidense han incorporado las esferas cultural, educativa, intelectual y tecnocientífica al marco de las estrategias diplomáticas desplegadas desde Washington. Muchos de estos trabajos se refieren a instituciones públicas creadas en vísperas o al calor de la Segunda Guerra Mundial -como la Office of Inter-American Affairs (OIAA), la División de Relaciones Culturales del Departamento de Estado, el Institute of Inter-American Affairs (IIAA) y el Interdepartmental Committee on Cooperation with the American Republics (ICCAR)- y coinciden en señalar que América Latina funcionó como una suerte de "terreno de prueba" de la ingeniería institucional de relaciones tecnocientíficas y culturales internacionales, expandida durante la posguerra al resto del mundo y, en particular, a los países en desarrollo ${ }^{22}$.

Paris, ORSTOM, 1996, pp. 171-185; Alexis de Greiff, "La norteamericanización de la tecno-ciencia en América Latina: diplomacia científica y hegemonía cultural", en Pablo Kreimer, Hebe Vessuri, Léa Velho y Antonio Arellano (coords.), Perspectivas latinoamericanas en el estudio social de la ciencia, la tecnología y la sociedad, México, Siglo XXI y Foro Consultivo Científico y Tecnológico, 2014, pp. 194-207; Mauricio Nieto Olarte, Remedios para el Imperio: historia natural y la apropiación del Nuevo Mundo, Bogotá, Instituto Colombiano de Antropología e Historia, 2000; Gabriela Soto Laveaga, Jungle laboratories: Mexican peasants, national projects, and the making of the Pill, Durham, Duke University Press, 2009. La noción de "espacios de circulación de conocimiento" se discute en Kapil Raj, "Networks of knowledge, or spaces of circulation? The birth of British cartography in colonial South Asia in the late eighteenth century", in Global Intellectual History, vol. 2, n. ${ }^{\circ}$ 1, London, 2017, pp. 49-66. Disponible en https://doi.org/10.1080/23801883.2017.1332883. Para esta breve síntesis de la historiografía de la ciencia se tomaron algunos elementos de la contribución de Marcos Cueto y Matheus Alves Duarte Da Silva, "Trayectorias y desafíos en la historiografía de la ciencia y de la medicina en América Latina", en Asclepio. Revista de Historia de la Medicina y de la Ciencia, vol. 72, n. ${ }^{2}$, Madrid, 2020, p. 320. Disponible en https://doi.org/10.3989/asclepio.2020.21 [fecha de consulta: 20 de agosto de 2021].

${ }^{20}$ Camilo Quintero Toro, "La ciencia norteamericana se vuelve global: el Museo Americano de Historia Natural en Colombia”, en Revista Estudios Sociales, n. ${ }^{3}$ 31, Bogotá, 2008 pp. 48-59. Disponible en www. redalyc.org/articulo.oa?id=81503104 [fecha de consulta: 2 de agosto de 2021].

${ }^{21}$ Emily Rosenberg, Spreading the American Dream: American Economic and Cultural Expansion, 18901945, New York, Hill and Wang, 1982.

${ }^{22} \mathrm{Al}$ respecto pueden consultarse, además de Miller, op. cit.; José Manuel Espinosa, Inter-American beginnings of U.S. cultural: diplomacy, 1936-1948, Washington, D.C., Government Printing Office, 1976; Frank A. Ninkovich, The Diplomacy of Ideas: U.S. Foreign Policy and Cultural Relations, 1938-1950, Cambridge, Cambridge Uni- 
Según Clark Miller, desde la Segunda Guerra Mundial, los hacedores de la política exterior recuperaron la noción de "cooperación científica", tradicionalmente ligada al intercambio entre científicos e intelectuales, poniendo un nuevo énfasis en las relaciones entre los Estados para afrontar problemas globales o promover el desarrollo económico como base para la democracia y la seguridad global ${ }^{23}$. Los programas agrícolas de Estados Unidos en América Latina, que también involucraron intereses corporativos, expresan muy bien esta concepción. Ya no se trata solo de una tecnociencia que acompaña la expansión comercial, sino del involucramiento explícito de gobiernos, científicos y burocracias técnicas en programas preestablecidos.

\section{El entramado institucional estatal de Estados Unidos en América Latina: Politica exterior, relaciones tecnocientificas y agricultura}

Desde la víspera de la Segunda Guerra Mundial, Estados Unidos implementó una serie de cambios en la organización estatal de las relaciones exteriores, que implicaron la incorporación de expertos científicos y técnicos en la conducción de los asuntos internacionales. Una de las primeras expresiones de esas transformaciones fue la creación, en 1938, del Interdepartmental Committee on Cooperation with the American Republics (ICCAR), un organismo cuyo propósito era coordinar los "proyectos colaborativos científicos y técnicos" implementados por diversos departamentos de Estado en América Latina ${ }^{24}$. Algunos de esos proyectos, como los del USDA, estuvieron precedidos y acompañados por dispositivos legales, institucionales y diplomáticos que inauguraron nuevas “especialidades" en la diplomacia. Por ejemplo, en 1939, el USDA creó la Oficina de Relaciones Exteriores para la Agricultura (OFAR) y el Congreso aprobó una ley que autorizaba el establecimiento de estaciones experimentales en países latinoamericanos para el desarrollo de cultivos complementarios con los de Estados Unidos ${ }^{25}$. En forma paralela, el Servicio Exterior creó nuevas categorías de personal -inicialmente vinculado a sus operaciones en América Latina-, incluyendo agregados y asistentes agrícolas. El papel de la agricultura en la política exterior adquirió tal relevancia que, durante la guerra, se incorporaron sesenta y nueve agregados agrícolas al Servicio Exterior de Es-

versity Press, 1981; Justin Hart, Empire of Ideas: The Origins of Public Diplomacy and the Transformation of U.S. Foreign Policy, New York, Oxford University Press, 2013; Claude Erb, "Prelude to Point Four: The Institute of Inter-American Affairs”, in Diplomatic History, vol. 9, No. 3, Murfreesboro, 1985, pp. 249-269.

${ }^{23}$ Miller, op. cit., p. 136.

${ }^{24}$ Miller, op. cit. Para 1945, el ICCSC estaba integrado por veintiocho representantes de veinte agencias gubernamentales, entre las que se encontraban: el Servicio de Salud Pública, el Departamento de Agricultura, el Departamento de Comercio, la Oficina de Asuntos Inter-Americanos, la Civil Aeronautics Administration, la Agencia Federal de Obras Públicas, el Departamento de la Marina y la División de Relaciones Culturales del Departamento de Estado, además del Export-Import Bank. Su función era evaluar las solicitudes de recursos para los proyectos de cooperación de las diversas agencias en función de su adecuación a las políticas y objetivos del gobierno y diseñar el programa anual y el presupuesto. US-Department of State, Interdepartmental Committee on Cultural and Scientific Cooperation, Washington, Government Printing Office, 1945. Disponible en https://babel.hathitrust.org/cgi/pt?id=txu.059173023676808;view=1up;seq=7 [fecha de consulta: 24 de octubre de 2019].

${ }^{25}$ Kenneth A. Haines, "Los países amigos", en IICA-ALAF (comp.), Las ciencias agrícolas en América Latina: Progreso y futuro, San José de Costa Rica, IICA, 1967, p. 455. 
tados Unidos para colaborar con las tareas que, hasta 1939, desarrollaban apenas ocho $\operatorname{agregados}^{26}$.

Luego de la creación del ICCAR, el estallido de la guerra inauguraría una activa política para la puesta en marcha de los "proyectos colaborativos técnicos y científicos" de los diversos departamentos, entre los que se encontraban los proyectos agrícolas del USDA. En mayo de 1940, ante un auditorio compuesto por los funcionarios y expertos agrícolas latinoamericanos que concurrieron al Octavo Congreso Científico Americano, el secretario de Agricultura, Henry Wallace, propuso la creación del Instituto Inter-Americano de Ciencias Agrícolas y presentó su proyecto agrícola para la región, enlazando la solidaridad hemisférica con la complementariedad productiva:

"Estos países [americanos] producen el mismo tipo de commodities agrícolas. Como están las cosas hoy, por lo tanto, las líneas de producción en las Américas y la naturaleza de las mercancías intercambiadas entre las repúblicas presentan definitivamente deficiencias para una sustancial expansión del comercio. Esto enfatiza la necesidad de explorar las posibilidades de una mayor producción agrícola tropical o subtropical en América Latina, que Estados Unidos necesita y puede importar sin inconvenientes en cantidades sustanciales [...]. En consecuencia, esto incrementaría el poder de compra de nuestros vecinos latinoamericanos para una amplia variedad de productos que quieren de este país pero que, en las presentes circunstancias, no pueden comprar aquí. Finalmente, el desarrollo y expansión de la producción de productos complementarios no competitivos suministraría la punta de lanza de nuestros esfuerzos cooperativos diseñados para darle un significado práctico a la idea de la solidaridad panamericana"27.

Un mes después del Octavo Congreso, el Senado de Estados Unidos aprobaba una asignación de USD 500000 al USDA para iniciar el programa de investigación y cultivo de Hevea en América Latina.

Ese mismo año, el presidente Franklin D. Roosevelt le encargó a Nelson Rockefeller la conducción de la recientemente creada Office of Inter-American Affairs (OIAA), una institución de emergencia que estaba destinada a coordinar iniciativas públicas y privadas en una amplia gama de programas vinculados a la defensa hemisférica y -según la retórica- a la lucha por la libertad y la democracia, evitando los procedimientos burocráticos característicos del Departamento de Estado ${ }^{28}$. De hecho, la OIAA colaboró o gestionó programas complementarios con los de las diversas agencias integrantes del

${ }^{26}$ Elton Atwater, “The American Foreign Service since 1939", in The American Journal of International Law, vol. 41, No. 1, Cambridge, 1947, p. 80. No es casual que, a partir de la década de 1940, la Fundación Rockefeller haya complementado su tradicional énfasis en programas de salud pública con programas para la promoción de la agricultura en la región. Al respecto véase Marcos Cueto, "Introduction", in Cueto, op. cit., pp. IX-XX; Vessuri, "Foreign scientists...”, op. cit.; Vessuri, "Scientific Cooperation...”, op. cit.

${ }^{27}$ Henry A. Wallace, "The Vital role of Agriculture in Inter-American Relations", in Proceedings of the Eight American Scientific Congress, vol. V, Agriculture and Conservation, Washington, 1942, p. 18. Disponible en https://books.google.com.ar/books?id=cgIFAQAAIAAJ\&printsec=frontcover\&hl=es\&source= gbs_ge_summary_r\&cad $=0 \# \mathrm{v}=$ onepage $\& \mathrm{q} \& \mathrm{f}=$ false_[fecha de consulta: 2 de marzo de 2020]

${ }_{28}$ Gisela Cramer \& Úrsula Prutsch, "Nelson A. Rockefeller's Office of Inter-American Affairs and the Quest for Pan-American Unity: An Introductory Essay”, in Gisela Cramer \& Úrsula Prutsch (eds.), ;Américas unidas! Nelson A. Rockefeller's Office of Inter-American Affairs (1940-46), Frankfurt am Main / Madrid, Vervuert / Iberoamericana, 2012, pp. 15-51. 
ICCAR y de otras agencias públicas, como las corporaciones subsidiarias de la Reconstruction Finance Corporation (Rubber Reserve Company, Metals Reserve Company, Defense Supplies Corporation), también creadas en 1940 para asegurar el abastecimiento de materias primas estratégicas ${ }^{29}$. Luego de Pearl Harbor, muchas de estas corporaciones firmaron acuerdos bilaterales con países latinoamericanos para la venta de sus excedentes de materiales estratégicos. En 1943, por ejemplo, la Rubber Reserve Company -a partir de entonces denominada Rubber Development Corporation- operaba en dieciséis países de la región a través de distintos tipos de acuerdos, que apuntaban a intensificar sus esfuerzos para obtener caucho de diversos géneros de plantas mayormente silvestres, aunque también de plantación. Según los acuerdos, los países respetarían determinados topes para el consumo interno y exportarían a Estados Unidos todo el excedente a una escala de precios fija, elaborada en función del tipo y calidad del caucho ${ }^{30}$.

En contrapartida, algunos de los países que participaban del programa de desarrollo de cultivos complementarios y extracción de minerales estratégicos recibieron créditos del Export-Import Bank para financiar la compra en Estados Unidos de materiales y equipamiento requerido para el desarrollo de obras públicas -en especial, vías de comunicación-, proyectos agrícolas, mineros o industriales, bajo el supuesto de que los créditos se pagarían con la venta de productos complementarios. Algunos de los acuerdos involucraron la creación de corporaciones -en ocasiones, con representación estadounidense en sus directorios- para gestionar la comercialización de productos estratégicos. En otros casos - como en Perú- también estipulaban la participación de la OFAR en el establecimiento de estaciones experimentales en zonas de cultivos complementarios, dirigidas por expertos estadounidenses y ligadas a proyectos de colonización y apertura de la frontera agrícola ${ }^{31}$. De hecho, la OFAR instalaría estaciones experimentales en Perú

${ }^{29}$ Donald W. Rowland, History of the Office of the Coordinator of Inter-American Affairs. Historical Reports of War Administration, Washington, Government Printing Office, 1947, p. 218. Disponible en https://babel.hathitrust. org/cgi/pt?id=mdp.39015014125036;view=1up;seq=7;size=200 [fecha de consulta: 20 de febrero de 2020].

${ }^{30}$ Durante la guerra, la Hevea proveyó la mayor proporción de caucho proveniente de América Latina. Sin embargo, también se explotaron otros géneros como Castilla elástica (del sudeste de México, América Central y el noroeste de Sudamérica), Guayule (de zonas secas del norte de México) y Manicoba (de las regiones secas del nordeste de Brasil). Douglas H. Allen, "Statement of Douglas H. Allen, President, Rubber Development Corporation", in Hearings before a Subcommittee of the Committee of Agriculture and Forestry of the Senate, Washington, United States Senate, Seventy-Eight Congress, Part 7, December 9, 1943, p. 2111. Disponible en https://books.google.com.ar/books?id=_CdEWWp1aCsC\&pg= PA2099\&lpg =PA2099\&dq=Douglas + H. + Allen, $+\%$ E2 $\% 80 \% 9$ CStatement + of + Douglas + H. + Alle $\mathrm{n},+$ President, + Rubber + Development + Corporation $\%$ E2\% $\% 0 \% 9 \mathrm{D},+\mathrm{en}+$ Hearings + before $+\mathrm{a}+\mathrm{Subco}$ mmittee + of + the + Committee + of + Agriculture + and + Forestry + of + the + Senate $\&$ source $=$ bl $\&$ ots $=5 \mathrm{PW}$ o7arcts\&sig=ACfU3U10RQ_ZpvFB-XHHmIN7mU9_pTrkYA\&hl=en\&sa=X\&ved=2ahUKEwi0e7yhM7tAhV2K7kGHb2HBy4Q6AEwAXoECAIQAg\#v=onepage\&q=Douglas $\% 20 \mathrm{H} . \% 20 \mathrm{Allen} \% 2 \mathrm{C} \% 20$ $\%$ E2\%80\%9CStatement $\% 20$ of $\% 20$ Douglas $\% 20$ H. $\% 20$ Allen $\% 2$ C $\% 20$ President $\% 2$ C $\% 20$ Rubber $\% 20$ Development $\% 20$ Corporation $\%$ E2\%80\%9D $\% 2 C \% 20$ en $\% 20$ Hearings $\% 20$ before $\% 20 a \% 20$ Subcommittee $\% 20$ of $\% 20$ the $\% 20$ Committee $\% 20$ of $\% 20$ Agriculture $\% 20$ and $\% 20$ Forestry $\% 20$ of $\% 20$ the $\% 20$ Senate $\& f=$ false [fecha de consulta: 5 de mayo de 2020]; Harry J. Fuller, "War-Time rubber exploitation in tropical America", in Economic Botany, vol. 5, No. 4, New York, 1951, pp. 311-337.

${ }^{31}$ La descripción de esta política, que involucra el otorgamiento de créditos, el mapeamiento del territorio para identificar recursos estratégicos, la firma de acuerdos para la exportación de los excedentes, creación de corporaciones y el establecimiento de estaciones experimentales se basa en los trabajos de Cuvi, "Las 
(1942), Ecuador (1942), El Salvador (1942), Cuba (1943), Nicaragua (1943) y Guatemala $(1944)^{32}$. A diferencia de los acuerdos con la Rubber Reserve Company, que tenían objetivos de corto plazo, las estaciones respondían a los objetivos de más largo plazo del USDA, que apuntaba a transformar el escenario rural de la región.

Paralelamente, en 1942, la OIAA creó el Institute of Inter-American Affairs (IIAA), una corporación autónoma encargada de implementar programas de "salud y saneamiento" y "provisión de alimentos" a través de la creación de unidades administrativas denominadas "servicios", que funcionaban bajo dependencia de los respectivos ministerios (agricultura o salud), aunque, en general, bajo la dirección de personal estadounidense. A pesar de que en los discursos se lo presentaba como una contribución a la salud y la alimentación popular, durante la guerra, la mayoría de los proyectos del IIAA se desarrolló en zonas de extracción de recursos críticos -tanto minerales como caucho de plantas silvestres- $\mathrm{y}$ de instalación de tropas estadounidenses o contingentes de trabajadores vinculados a obras de infraestructura estratégica ${ }^{33}$. El programa de "provisión de alimentos", que se expandió en forma significativa durante la posguerra, se proponía incrementar la producción creando servicios de extensión diseñados según el patrón agrícola estadounidense: variedades más productivas, uso de fertilizantes e incorporación de maquinaria ${ }^{34}$.

La asistencia técnica provista por el IIAA y los proyectos colaborativos científicos y técnicos del USDA se complementaron, a su vez, con la puesta en marcha de programas educativos que apuntaban a formar cuadros técnicos y científicos. Desde 1942, por ejemplo, la OIAA y el Departamento de Estado organizaron un programa de formación supervisado por la Oficina de Economía Agrícola del USDA que, entre 1942 y 1944, formó unos veinte agrónomos latinoamericanos en diversas temáticas de economía agrícola, como administración de créditos rurales, administración y contabilidad de granjas, cooperativas agrícolas y estadística agrícola ${ }^{35}$. Para 1945, diversas oficinas del USDA, como el Servicio de Conservación de Suelos, el Servicio de Extensión y la Administración de Investigación Agrícola habían implementado programas similares, que proveían formación on-the-job en diversas oficinas, laboratorios o estaciones del USDA y en escuelas

semillas...”, op. cit.; Cuvi, "Dejen que...”, op. cit.; Cuvi, “The Cinchona Program...”, op. cit.; Cuvi, "Mapas confidenciales...", op. cit. Referencias a este tema también se encuentran en Wilson Picado Umaña, "En busca de la genética guerrera. Segunda Guerra Mundial, cooperación agrícola y Revolución Verde en la agricultura de Costa Rica", en Historia Agraria, n. ${ }^{\circ}$ 56, Murcia, 2012, pp. 107-134.

${ }^{32}$ Technical Cooperation Administration, Point 4 Projects, Washington, 1952. Disponible en https://books. google.com.ar/books?id=yP489RV7jJYC\&printsec=frontcover\&hl=es\&source=gbs_ge_summary_r\&cad=0\# $\mathrm{v}=$ onepage $\& \mathrm{q} \& \mathrm{f}=$ false [fecha de consulta: 30 de noviembre de 2019].

${ }^{33}$ Rowland, op. cit.; Erb, op. cit.; Picado, op. cit.; André L. Vieira de Campos, "The Institute of Inter-American Affairs and its health policies in Brazil during World War II", in Presidential Studies Quarterly, No. 28, vol. 3, Washington D.C, 1998, pp. 523-534.

${ }^{34}$ Wilson Picado Umaña y José A. Fernández Molina, "Programas agrícolas de Estados Unidos en América Latina desde la Segunda Guerra Mundial. Entre el mejoramiento de plantas y la clonación de instituciones (1939-1955)", en XV Congreso Internacional de Historia Agraria, Lisboa, 28-30 de enero de 2016.

35 Carl. F. Taeusch, "Toward Practical Cooperation", in Agriculture in the Americas, vol. IV, No. 6, Washington D.C., 1944, pp. 107-109 \& 112. Disponible en: https://hdl.handle.net/2027/umn.31951d00045071 j? urlappend $=\% 3$ Bseq $=839$ [fecha de consulta: 25 de mayo de 2020]. 
agrícolas universitarias ${ }^{36}$. Se trataba de programas financiados a través de diferentes arreglos (cofinanciados, financiados por el país de origen del visitante o por Estados Unidos), en cuyo marco se formaron, entre 1942 y 1948, unos 257 latinoamericanos, algunos de los cuales trabajaban en estaciones experimentales de la OFAR ${ }^{37}$. Uno de los propósitos era familiarizar a los visitantes con la organización institucional y los métodos tecnocientíficos de la agricultura estadounidense, por lo que el financiamiento se otorgaba a personas comprometidas en servicios gubernamentales, que pudieran aplicar su experiencia al regreso de su estadía ${ }^{38}$. Adicionalmente, en 1946 comenzaría a funcionar en Costa Rica, bajo la órbita de la Unión Panamericana, el Instituto Interamericano de Ciencias Agrícolas (IICA) propuesto por Henry Wallace, donde se formarían posgraduados en agricultura y ganadería tropical, incluyendo especializaciones en cultivos comerciales -como café y cacao-, cultivos estratégicos -como abacá y caucho-, vegetales y alimentos básicos -como maíz-, economía rural, extensión, botánica y suelos ${ }^{39}$.

\section{Estados Unidos y las redes público-privadas \\ en la búsqueda de plantas productoras de caucho: \\ Los antecedentes del programa de cultivo de Hevea}

Como señalé, la presión británica sobre el precio del caucho a principios de la década de 1920 condujo a Estados Unidos a realizar esfuerzos sistemáticos, tanto públicos como privados, para el desarrollo de plantas de caucho en territorio nacional y en América Latina. En 1923, a poco de que Harvey Firestone iniciara una campaña para romper con el control británico emulando la estrategia de la United States Rubber Company y

${ }^{36}$ U.S. Department of State, Inter-departmental Committee..., op. cit., p. 14; William X. Hull, “'In - Service' Training Pays", in Agriculture in the Americas, vol. V, No. 10, Washington D.C., 1945, pp. 187-189 y 194. Disponible en https://hdl.handle.net/2027/txu.059173026652282?urlappend=\%3Bseq=201 [fecha de consulta: 2 de junio de 2020].

${ }^{37}$ Lewis U. Hanke, Inter-American Technical and Cultural Cooperation. United States Participation: 19381948. Report for the U.S. Delegation to the $9^{\text {th }}$ Inter-American Conference of American States, Washington, U.S. Government Printing Office, 1948, p. 17. Disponible en https://books.google.com.ar/books?id=LXpQAAAA MAAJ\&pg=PA43\&lpg=PA43\&dq=hanke + inter-american + technical + and + cultural + cooperation \&source $=$ bl \& ots=RaSoecbiS8\&sig=ACfU3U20c4JF8pnk15ZwBE-qCIldPqZvOg\&hl=en\&sa=X\&ved=2ahUKEwjppfGKq 83tAhUHrJ4KHaFSCQEQ6AEwAnoECAEQAg\#v=onepage \&q=hanke $\% 20$ inter-american $\% 20$ technical $\% 20$ and\%20cultural\%20cooperation\&f=false [fecha de consulta: 9 de mayo de 2020]; Ross Moore, "Agricultural Cooperation with the American Republics", in U.S-Department of State: The program of the Interdepartmental Committee on Scientific and Cultural Cooperation, Washington, Government Printing Office, 1947, p. 8. Disponible en https://babel.hathitrust.org/cgi/pt?id=txu.059173023676910; view=1up;seq=13 [fecha de consulta: 5 de marzo de 2020].

${ }^{38}$ Hull, op. cit.; U.S. Department of State, Inter-departmental Committee..., op. cit., p. 14. En 1946, el director del Servicio de Extensión de la Universidad de Arkansas, que recorrió Ecuador, Colombia, Nicaragua, El Salvador, Guatemala y México para estudiar los programas agrícolas llevados a cabo en colaboración con Estados Unidos, recomendaba que dichos países estudiaran las tres divisiones del sistema institucional agrícola estadounidense (land-grant colleges, estaciones experimentales y extensión) para adaptarlo a las condiciones de los respectivos países. Aubrey D. Gates, "Let's cooperate", in Agriculture in the Americas, vol. VI, No. 5, Washington D.C., 1946, pp. 46 \& 84-85. Disponible en https://hdl.handle.net/2027/uiug.301120453 46175? urlappend $=\% 3$ Bseq $=89$ [fecha de consulta: 2 de junio de 2020].

${ }^{39}$ Rogelio Coto, "El IICA y la OEA", en IICA-ALAF, op. cit., pp. 465-506; Picado, op. cit.; Cuvi, "Dejen que...", op. cit. 
la Goodyear Tire and Rubber Company, que habían establecido plantaciones de Hevea en Malasia y Sumatra durante la década anterior, el Congreso aprobó una asignación de USD 400000 al Departamento de Comercio (USDC), y de USD 100000 al USDA, que les permitió enviar dos equipos técnicos a explorar las posibilidades de establecer plantaciones de caucho en América Latina y en Filipinas ${ }^{40}$. Los informes de las expediciones enviadas a América Latina tenían como propósito presentar "los factores físicos, económicos y políticos que deberían considerar los potenciales inversores para juzgar la posibilidad de establecer plantaciones de caucho"41.

Los expertos realizaron un estudio en Trinidad y Surinam sobre una cuestión que sería clave: el mal sudamericano de la hoja, una enfermedad causada por el hongo Dothidela ulei, que afectaba al género Hevea y, a diferencia de lo que sucedía en el Sudeste Asiático (cuyas plantaciones se habían originado en Hevea brasiliensis llevado de Brasil), era uno de los factores de riesgo para el desarrollo de plantaciones en América Latina (Fig. 1) ${ }^{42}$. Muchas de las semillas de Hevea brasiliensis recolectadas en esas expediciones fueron plantadas en los Summit Plant Introduction Gardens de la zona del canal de Panamá, junto con otros géneros potencialmente útiles para la extracción de caucho ${ }^{43}$. En forma complementaria, el USDA instaló una estación experimental de plantas de caucho en Haití y expandió sus terrenos de investigación a Chapman Field, cerca de Miami (Florida), donde se estableció un centro de investigación e introducción de plantas importadas, en especial, de zonas tropicales ${ }^{44}$.

\footnotetext{
${ }^{40}$ Finlay, op. cit., pp. 3-7 \& 55-56.

${ }^{41}$ William L. Schurz, O. D. Hargis, Curtis F. Marbut \& Courtland B. Manifold, Rubber production in the Amazon Valley, Washington, Department of Commerce, Bureau of Foreign and Domestic Commerce, 1925, p. VII. Disponible en https://babel.hathitrust.org/cgi/pt?id=uiug.30112000600103\&view=1up\&seq=1 [fecha de consulta: 30 de mayo de 2020].

${ }^{42}$ Robert D. Rands \& Loren G. Polhamus, Progress Report on the Cooperative Hevea Rubber Development in Latin America, Washington D.C., U.S. Department of Agriculture, 1955, p. 15. Disponible en https://ia803204.us.archive.org/1/items/progressreporton976rand/progressreporton976rand.pdf [fecha de consulta: 29 de noviembre de 2019]; USDA, Research and Related Services in the United States Department of Agriculture (vol. II). Prepared for the Committee on Agriculture of the House of Representatives, Eighty-first Congress, Second Session, December 21st, 1950, Washington, Government Printing Office, 1951, p. 1428 .

${ }^{43}$ Holger Johansen, Annual Report of the Canal Zone Plant Introduction Gardens for the Fiscal Year 1924, Mont Hope C.Z., The Panama Canal Press, 1924, p. 4. Disponible en https://books.google.com.ar/books?id= p8stAAAAIAAJ\&printsec $=$ frontcover $\& \mathrm{hl}=\mathrm{es} \&$ source $=\mathrm{gbs}$ ge_summary_r\&cad $=0$ \# $\mathrm{v}=$ onepage $\& \mathrm{q} \& \mathrm{f}=\mathrm{false}$ [fecha de consulta: 17 de abril de 2020]. Los Summit Gardens se fundaron en 1923 y, en 1944, albergaban unas diez mil especies diferentes, recolectadas en diversas regiones tropicales del mundo a partir de las expediciones de su propio personal, contribuciones del USDA y de otros países. El objetivo era evaluar la adaptabilidad de las plantas introducidas en la zona del canal y a zonas comparables de la América tropical. Durante la guerra, esta estación colaboraría estrechamente con los proyectos de cultivos complementarios del USDA en América Latina. Entre otros servicios, proveyó medio millón de semillas de Hevea a viveros en Colombia, Ecuador y Venezuela. E. C. Higbee, "The Canal Zone Experiment Gardens", in Agriculture in the Americas, vol. IV, No. 8, Washington D.C., 1944, pp. 146-147-156. Disponible en https://hdl.handle.net/2027/ umn.31951d00045071j?urlappend=\%3Bseq=878 [fecha de consulta: 7 de junio de 2020].

${ }^{44}$ Finlay, op. cit., pp. $60 \& 64$.
} 
Figura 1

Árbol de Hevea desfoliado

por el mal sudamericano de la hoja (izq.) y árbol sano (der.)
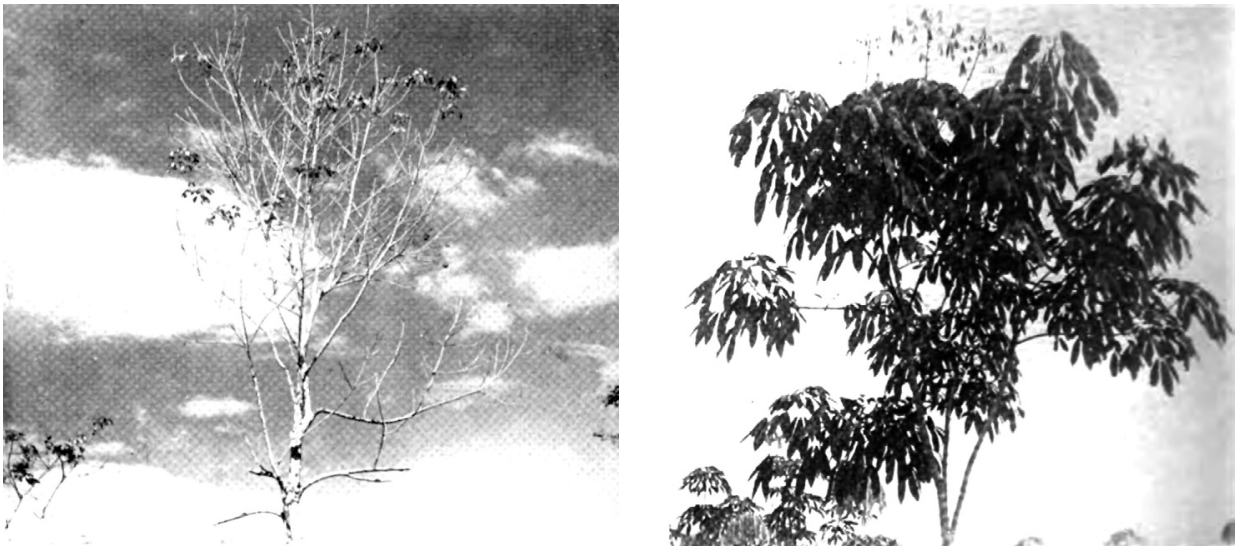

Árbol de hevea desfoliado por el mal sudamericano

Árbol de hevea sano. de la hoja.

Fuente: Michael H. Langford, "Science's Fight for Healthy Hevea", in Agriculture in the Americas, vol. IV, No. 8, Washington D.C., p. 152. Disponible en https://hdl.handle.net/2027/umn.31951d00045071j?urlappend= $\% 3$ Bseq=884 [fecha de consulta: 6 de septiembre de 2021]

La campaña de Harvey Firestone y la decisión de asignar recursos para las expediciones contaron con un fuerte apoyo del entonces secretario de Comercio, Herbert Hoover, quien no solo impulsó la plantación experimental de caucho en los Summit Gardens, sino que, también, tentó a la United Fruit Company para que invirtiera en plantaciones de caucho en América Central ${ }^{45}$. En 1924 la empresa inició un primer experimento en la zona del río Reventazón de Costa Rica, que abandonó en $1925^{46}$. Entre 1926 y 1927 instalaría una estación experimental y un jardín de introducción en plantas en el Valle de Lancetilla, Honduras, donde plantó quinientos árboles de Hevea ${ }^{47}$.

También a principios de la década de 1920, prominentes figuras de la industria, como Thomas Edison, Henry Ford y Harvey Firestone comenzaron a movilizar esfuerzos de investigación con plantas domésticas y con otras provenientes de diversos países. Además de establecer sus propios terrenos experimentales para el estudio de diferentes géneros y especies, estos empresarios formaron una verdadera red de colaboración

${ }^{45}$ Finlay, op. cit., p. 63.

${ }^{46}$ Ronny Viales Hurtado, “La coyuntura bananera, los productos 'complementarios' y la dinámica productiva empresarial para la exportación de la United Fruit Company en el Caribe costarricense. 1883-1934”, en Revista de Historia, n. ${ }^{\circ}$ 44, San José, 2001, p. 102.

${ }^{47}$ Edward T. Stanwood, "Hevea Rubber comes to Honduras", in Agriculture in the Americas, vol. 4, No. 12, Washington D.C., 1944, p. 227. Disponible en https://hdl.handle.net/2027/umn.31951d00045071j?urlappend=\%3Bseq=959 [fecha de consulta: 10 de junio de 2020]. La empresa decidió evaluar la viabilidad de aventurarse en otros cultivos en un momento en que la epidemia de la enfermedad de Panamá afectaba sus plantaciones de bananeras. Walter N. Bangham, "Plantation Rubber in the New World", in Economic Botany, vol. 1, No. 2, New York, 1947, pp. 210-229. 
con el USDA para el intercambio de material genético, información y conocimiento. En 1927, los tres empresarios constituyeron la Edison Botanic Research Corporation, una corporación dedicada a explorar fuentes naturales de caucho, a la que cada uno de ellos aportaría unos USD 25000 anuales $^{48}$. A su vez, la Goodyear Rubber Plantation Company adquirió una plantación en Filipinas (1928), la Firestone Tire and Rubber Company puso en marcha otra en Liberia (1926) y la Ford Motor Company se aventuró en Brasil, donde construyó una verdadera aldea agrícola destinada al cultivo de Hevea, conocida como Fordlandia $(1927)^{49}$.

La plantación de Ford se originó mayormente en la recolección de semillas de Hevea brasiliensis en los márgenes del río Tapajóz, cuyo rendimiento y resistencia no estaban garantizados. En 1933, preocupados por el lento crecimiento de los árboles, los directivos de Fordlandia decidieron contratar los servicios de asesoramiento de James M. Weir, que en la década de 1920 había participado de las exploraciones del USDC y el USDC en América Latina y luego trabajó en el Rubber Research Institute de Malasia y en una de las plantaciones de Goodyear en Sumatra. Además de detectar la presencia del mal sudamericano de la hoja en la plantación, James Weir propuso varias líneas de trabajo que fueron cruciales para el desarrollo del programa del USDA durante la guerra ${ }^{50}$.

Una de sus propuestas fue traer clones de alto rendimiento de Sumatra e injertarlos en raigones vigorosos, una técnica utilizada hacía más de una década en las colonias holandesas para reproducir material con las propiedades deseadas. El propio James Weir viajó a Sumatra para seleccionar los clones de la plantación de Goodyear y llevarlos a Brasil. Aunque la propuesta fue presentada como una vía para la implementación de prácticas de cultivo estandarizadas con miras a incrementar la productividad, James Weir tenía también una preocupación experimental: le interesaba testear la resistencia de los clones y comparar su productividad con especies nativas. Por eso, a su regreso de Sumatra (principios de 1934), propuso iniciar una nueva plantación a $50 \mathrm{~km}$ de Santarém, donde las condiciones eran mejores para el cultivo: el terreno era más plano, el clima más seco y el suelo más rico y con mejor drenaje. La nueva plantación, denominada Belterra ${ }^{51}$, sería el epicentro del emprendimiento productivo, mientras que Fordlandia quedaría como un centro de investigación, donde James Weir podía seleccionar especímenes, producir esquejes para la nueva plantación y entrenar trabajadores en las técnicas de injerto. A fines de 1935, luego de que la enfermedad adquiriera dimensión epidémica en Fordlandia, James Weir obtuvo sus primeros resultados: ninguno de los clones asiáticos era inmune al mal sudamericano de la hoja ${ }^{52}$.

\footnotetext{
${ }^{48}$ Finlay, op. cit., p. 87.

${ }^{49}$ El territorio de Fordlandia se extendía $120 \mathrm{~km}$ a lo largo de la ribera oriental del río Tapajóz. La ciudad construida por Ford contaría, entre otros servicios, con cloacas, acueductos para la distribución de agua potable, $50 \mathrm{~km}$ de caminos por las que circulaban los modelos Ford T y Ford A, un puerto, tres escuelas, un hospital con cien camas, iglesias, cancha de golf, piscinas, doscientas casas con jardines de flores y vegetales y barracas para mil hombres solteros. Greg Grandin, Fordlandia: The Rise and Fall of Henry Ford's Forgotten Jungle City, New York, Metropolitan Books, 2009, p. 19; Davis, op. cit., p. 624.

${ }^{50}$ Dean, op. cit., pp. 75-76.

${ }^{51}$ En poco tiempo, Belterra se convirtió en una aldea similar a Fordlandia, pero a mayor escala, con unas ochocientas casas. Grandin, op. cit., p. 295; Davis, op. cit., p. 626.

${ }^{52}$ Dean, op. cit., pp. 75-77.
} 
A su vez, James Weir comenzó a seleccionar especímenes resistentes en Fordlandia y propuso realizar exploraciones para identificar especies o variedades que pudieran ser resistentes $-\mathrm{y}$, en el mejor de los casos, de alto rendimiento. El propósito era utilizarlas como injertos de copa o, bien, como material para un programa de cruzamiento. En ese marco, visitó las viejas plantaciones de las Guayanas, realizó una expedición al Río Negro para traer semillas de Hevea benthamiana, Hevea spruceana y Hevea guianensis -aparentemente resistentes- y recolectó semillas en la boca del Amazonas, cerca de Belém, que fueron plantadas en Belterra ${ }^{53}$. Renunció en 1938, pero Charles H. Townsend, su colaborador, realizó dos viajes más de recolección al estado de Acre. En 1939, comenzaría a realizar experimentos de polinización, cuyos híbridos esperaba plantar primero en los viveros de Fordlandia para trasladarlos, luego, a Belterra ${ }^{54}$.

En la primera mitad de la década de 1930, la apuesta de Ford por el cultivo de Hevea en América Latina parecía perfilarse como una alternativa viable: en 1932 Goodrich instaló una plantación experimental en República Dominicana y, en 1935, Goodyear acordó establecer en los Summit Gardens viveros con material genético de sus plantaciones en Filipinas, que luego llevaría a la plantación experimental que instaló en Panamá, cerca del lago Gatún ${ }^{55}$. La estrategia de Goodyear estuvo motivada por el nuevo escenario generado por la Gran Depresión: en 1934, ante la caída del precio del caucho, se firmó el Acuerdo Internacional de Restricción del Caucho, que no solo limitó su producción y plantación en el Sudeste Asiático, sino que prohibió la circulación de plantas fuera de los países que lo firmaron. Dado que Filipinas no lo había suscrito, Goodyear tenía la colección más grande de clones fuera del área de restricción. En 1936, la empresa compró las cuatrocientas hectáreas de la plantación de caucho que la United Fruit Company había abandonado en Costa Rica ${ }^{56}$. La compra de esta plantación tenía fines más bien experimentales, pues los expertos de Goodyear conocían la enfermedad y su incidencia en ese país: "Si la enfermedad podía combatirse con éxito en ese bastión -afirmaba el vicepresidente de Goodyear Plantations Co. en 1941- podía derrotarse en cualquier otro lugar" ${ }^{57}$. Coincidiendo con lo anterior, en 1937 el USDA iniciaría un programa de selección de cepas de Hevea resistentes en Costa Rica y Panamás8.

Sin embargo, cuando se inició la Segunda Guerra Mundial ninguno de los proyectos había obtenido resultados que garantizaran una fuente de abastecimiento segura. En mayo de 1940, en el marco de su campaña para impulsar la investigación y el desarrollo de cultivo de Hevea en América Latina, Henry Wallace se reunió con representantes de Ford, Goodyear, Goodrich, Firestone, US Rubber Company y UFCo, con las que llegó a un acuerdo unánime sobre la necesidad de que el gobierno avanzara sobre el territorio

\footnotetext{
${ }^{53}$ Dean, op. cit., pp. 76 \& 79. Grandin, op. cit., p. 300.

${ }^{54}$ Dean, op. cit., p. 81. Grandin, op. cit., p. 295.

${ }^{55}$ Dean, op. cit., p. 84. Rands \& Polhamus, op. cit.; J. Edgar Higgins, Annual Report of the Canal Zone Plant Introduction Gardens for the Fiscal Year 1935, Mont Hope C.Z., The Panama Canal Press, 1935. Disponible en https://books.google.com.ar/books?id=p8stAAAAIAAJ\&pg=RA1-PA69\&dq=annual +report + of $+\mathrm{t}$ he + canal + zone + plant + introduction + gardens + fiscal + year $+1935 \& h l=$ es\&sa $=$ X\&ved $=2$ ahUKEwjziZWoydLtAhV 5IbkGHfpvAP0Q6AEwAHoECAAQAg\#v=onepage \&q=annual $\% 20$ report $\% 20$ of $\% 20$ the $\% 20$ canal $\% 20$ zone $\% 20$ plant\%20introduction\%20gardens\%20fiscal\%20year\%201935\&f=false [fecha de consulta: 17 de abril de 2020].

${ }^{56}$ Bangham, op. cit., p. 217.

${ }^{57}$ Blandin, op. cit., p. 6.

${ }^{58}$ USDA, op. cit., p. 1428.
} 
latinoamericano en su estrategia de búsqueda de nuevas fuentes de caucho. Un mes más tarde, el Senado aprobaba los recursos para iniciar el proyecto ${ }^{59}$.

\section{FigURA 2}

Ilustración de la exploración inicial para el programa de Hevea

(Revista Agriculture in the Americas)

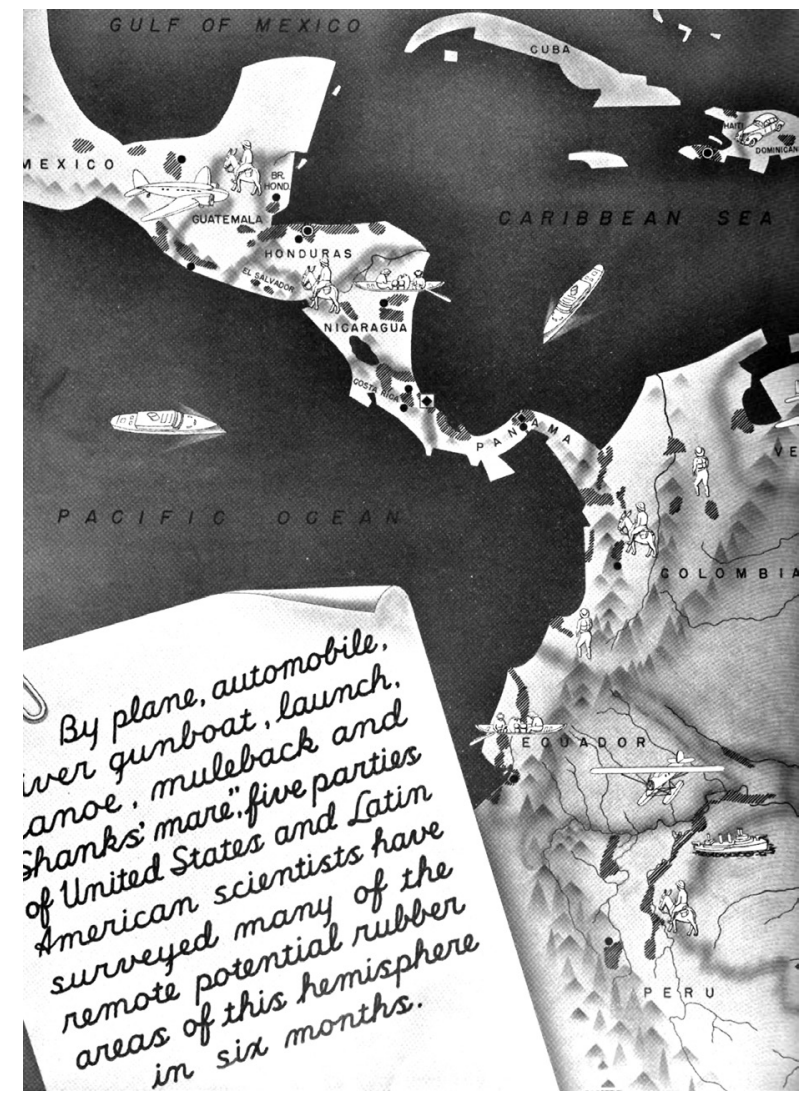

Fuente: E. W. Brandes, "Rubber on the Rebound-East to West", in Agriculture in the Americas, Washington D. C., April 1941, p. 6. Disponible en https://hdl.handle.net/2027/umn.31951d00045071j?urlappend=\%3 Bseq=53 [fecha de consulta: 20 de mayo de 2020].

${ }^{59}$ Earl N. Bressman, "Statement submitted by Dr. Earl N. Bressman, Director, Agricultural Division, Office of the Coordinator of Inter-American Affairs, to the Defense Investigating Committee of the Senate", in Investigation of the National Defense Program. Hearings before a Special Committee Investigating the National Defense Program, United States Senate, Seventy Seventh Congress, First Session, Government Printing Office, Washington, May 9, 1942, pp. 4942-4955. Disponible en https://books.google.com.ar/book $\mathrm{s}$ ? id=gm3InA2SAkQC\&lpg=PA4942\&ots=as 7Il2ME02\&dq=bressman $\% 20$ Hearings $\% 20$ before $\% 20 \mathrm{a} \% 20$ Special\%20Committee \%20Investigating\%20the\%20National\%20Defense $\% 20$ Program\&hl=es\&pg=PA372 $1 \# \mathrm{v}=$ onepage \&q=bressman $\% 20$ Hearings $\% 20$ before $\% 20 \mathrm{a} \% 20$ Special $\% 20$ Committee $\% 20$ Investigating $\% 20$ the $\% 20$ National $\% 20$ Defense $\% 20$ Program\&f=false [fecha de consulta: 5 de mayo de 2020]. 
El primer paso fue el envío de cuatro equipos técnicos estadounidenses, integrados por botánicos, patólogos, especialistas en suelos y expertos en caucho que, entre 1940 y 1941, realizaron exploraciones en quince países de América Latina para sondear las posibilidades (políticas y ambientales) de desarrollo del cultivo (Fig. 2) ${ }^{60}$. El propósito de estas expediciones era bien diferente de aquellas de la década de 1920, que apuntaban a ofrecer información para iniciativas privadas. En aquellos años de auge de expansión de las corporaciones estadounidenses en América Latina, todavía se concebía un tipo de imperialismo alternativo al europeo, regido por intereses privados en lugar de ministerios gubernamentales ${ }^{61}$. Por el contrario, las expediciones de 1940 fueron el puntapié inicial de un proyecto de investigación y desarrollo en el que el USDA intervendría de manera directa con estaciones de investigación y recursos materiales, humanos, cognitivos y genéticos, en estrecha colaboración con grandes empresas.

\section{El Programa de Cultivo de Hevea en América Latina: \\ INVESTIGACIÓN Y PRODUCCIÓN}

El involucramiento estadounidense con los recursos tropicales tuvo un punto de inflexión a fines del siglo XIX no solo en América Latina, sino, también, en el Sudeste Asiático, donde las corporaciones estadounidenses siguieron a las británicas y holandesas. Allí, los agrónomos se insertaron en la larga tradición colonial europea de la botánica, las enfermedades y los suelos tropicales. En las plantaciones de caucho en Sumatra, por ejemplo, holandeses y estadounidenses colaboraron en estudios fitopatológicos y en el proceso de mejoramiento de la Hevea, que permitieron un considerable incremento de su rendimiento en la década de $1920^{62}$. La experiencia adquirida tanto en el manejo de enfermedades como en el mejoramiento de las plantas y la organización de la producción fue clave para el programa en América Latina. De hecho, Robert Rands, uno de los líderes del programa, había trabajado muchos años en Sumatra y varios de los que participaron de esta iniciativa también habían pasado por el Lejano Oriente.

El programa para América Latina fue elaborado por el BPI y aprobado por la OFAR y contó con la colaboración de Ford, Goodyear y la UFCo., a las que pronto se sumó Firestone ${ }^{63}$.

\footnotetext{
${ }^{60}$ Brandes, "Rubber on the...”, op. cit., p. 6. y Cooperative Inter-American Plantation Rubber Development. Introduction, USDA, Washington D.C., 1946. Disponible en https://books.google.com.ar/books?id=y KEW23bhCnYC\&printsec $=$ frontcover\&hl $=$ es\&source $=$ gbs_ge_summary_r\&cad $=0 \# \mathrm{v}=$ onepage \&q\&f=false [fecha de consulta: 20 de mayo de 2020].

${ }^{61}$ Joseph Smith, The United States and Latin America. A history of American diplomacy, 1776-2000, London / New York, Routledge, 2005; Grandin, op. cit., p. 24.

62 Tucker, op. cit., p. 147.

${ }^{63}$ Esta articulación público-privada atravesó varios de los proyectos de desarrollo de cultivos complementarios. Nicolás Cuvi muestra que el "programa cinchona" (para el desarrollo de plantaciones de quina) del USDA contó con la colaboración de la farmacéutica Merck and Co., que desde 1934 había establecido plantaciones experimentales en Guatemala. Asimismo, cuando se inició la guerra, la UFCo llevaba varios años colaborando con el USDA en la conducción de experimentos con abacá en América Central y tenía ochocientas nueve hectáreas en cultivo en Panamá. En enero de 1942, el presidente de la compañía -por entonces asesor del Board of Economic Warfare- firmó un acuerdo con la Defense Supplies Corporation para impulsar el desarrollo del abacá en Panamá, Costa Rica, Honduras y Guatemala. Cuvi, "Dejen que...”, op.
} 
Aunque una vez finalizada la guerra Ford vendió sus plantaciones, Goodyear y Firestone continuaron participando del proyecto. Es posible que ambas empresas tuvieran como motivación -además de las incertidumbres de posguerra- la advertencia disparada por E. W. Brandes, otro de los directores del programa: "Dado que la enfermedad necesariamente seguirá a su huésped hacia Oriente [...] sus plantaciones son presas considerables para la enfermedad"64. De hecho, en 1949, Firestone inició un nuevo proyecto experimental en Guatemala y, a principios de la década de 1950, el Rubber Research Institute de Malasia acordó con Brasil un intercambio de material para obtener clones resistentes ${ }^{65}$.

El programa estaba previsto, en principio, con una duración de tres años y trazaba dos líneas de trabajo que implicaban diferentes grados de sofisticación técnica e incertidumbre sobre los resultados ${ }^{66}$. Una primera línea, de más largo plazo, mayor sofisticación y resultados más inciertos, recurriría a técnicas de fitomejoramiento para realizar cruces interespecies que condujeran a la obtención de semillas de híbridos de alto rendimiento y resistentes al mal sudamericano de la hoja. La segunda línea, que apuntaba a responder a la demanda de caucho en el mediano plazo, recurrió a las técnicas de la ingeniería hortícola para diseñar árboles con tres componentes: "(1) un raigón sin seleccionar, al que (2) se le injertaba el esqueje de una cepa asiática de alto rendimiento, pero muy susceptible (el llamado 'panel clone'), sobre el cual (3) se injertaba, a su vez, material de una cepa resistente" ${ }^{97}$.

En ambos casos, el primer problema era lograr la resistencia al mal sudamericano de la hoja, pues los clones de alto rendimiento podían obtenerse en las plantaciones de empresas estadounidenses en Filipinas y Liberia. El segundo problema era que las plantaciones tuvieran un rendimiento y un costo equivalente a las del Sudeste Asiático. En ese marco, el vicepresidente de Goodyear Plantations Co. advertía:

"Si resolvemos los problemas científicos y obtenemos árboles de alto rendimiento resistentes a la enfermedad en América Latina, el problema económico subsiste. El caucho debe producirse a largo plazo a un precio razonable, comparable al de Cercano Oriente y más barato que los sintéticos [...] a pesar de su mayor costo de mano de obra" ${ }^{\circ}$.

Los expertos estadounidenses sabían que el proceso de obtención de híbridos que combinaran resistencia y rendimiento insumiría mucho más tiempo que los tres años previstos para el programa. En términos generales, la evaluación de una generación de híbridos podía insumir alrededor de diez años, pues, en el caso de que la planta creciera a un ritmo ra-

cit.; Reconstruction Finance Corporation, Hearings before the Subcommittees of the Committee on Appropriations, House of Representatives 82nd Congress, First Session on the Supplemental Appropriation Bill for 1952, Part 2, June 21, 1951, Washington, Government Printing Office, p. 114. Disponible en https://books. google.com.ar/books?id=Ad-E3xB-Sp8C\&pg=RA1-PA114\&lpg=RA1-PA114\&dq=united +fruit + co. + rubber\&source=bl\&ots=eqk9IQ1qAR\&sig=ACfU3U2IUddKhk7Lr996k_Ao2Lqi4R-ddQ\&hl=es\&sa= X\&ved=2ahUKEwji7uWv_fTpAhWSA9QKHR5ZBEkQ6AEwFnoECAsQAQ\#v=onepage\&q=united $\% 20$ fruit $\% 20$ co.\%20rubber\&f=false [fecha de consulta: 3 de septiembre de 2020].

${ }^{64}$ Brandes, "Rubber on the...", op. cit., p. 6.

${ }^{65}$ H. Bos \& K. G. McIndoe, "Breeding of Hevea for resistance against Dothidella ulei P. Henn", in Journal of Rubber Research Institute of Malaya, vol. 19, Malaysia, 1965, pp. 98-107; Dean, op. cit., p. 113.

${ }^{66}$ Brandes, "Rubber on the...", op. cit.

${ }^{67}$ Rands \& Polhamus, op. cit., p. 7; Imle, op. cit., p. 271.

${ }^{68}$ Blandin, op. cit., p. 10. 
zonable, todavía había que evaluar la cantidad y calidad del látex del árbol maduro ${ }^{69}$. Aun así, el esfuerzo valía la pena porque el uso de híbridos disminuía los costos, los tiempos y el empleo de mano de obra en comparación con el uso de plantas de tres componentes. Los expertos no descartaban la eventualidad de que, en el testeo de otras especies y variedades de Hevea de la región del Amazonas o de clones de alto rendimiento provenientes de Liberia o Filipinas, se encontraran plantas que reunieran ambas propiedades ${ }^{70}$.

FiguRA 3

Mapa de centros cooperativos de investigación sobre caucho y proyectos cooperativos en América Latina (1955)

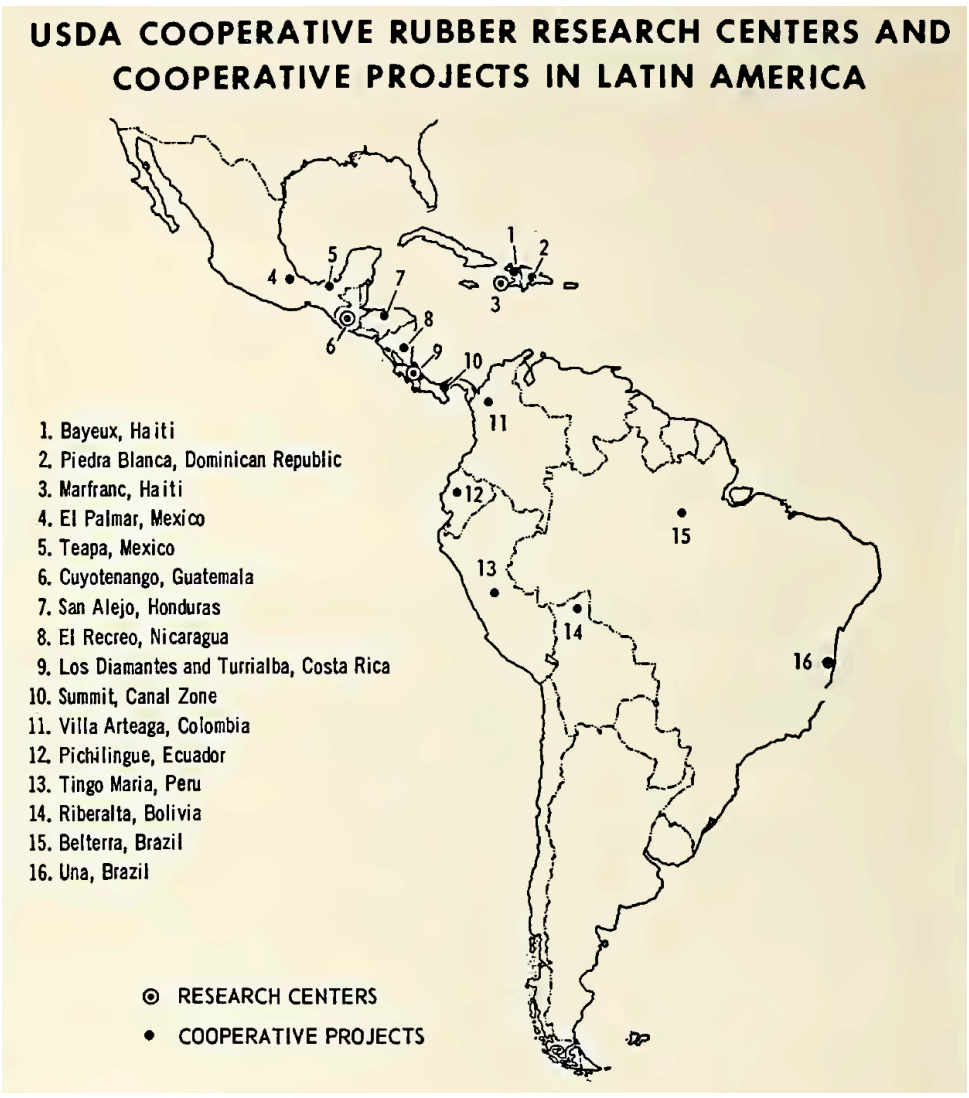

Fuente: Rands \& Polhamus, op. cit., p. 15.

${ }^{69}$ Rands \& Polhamus, op. cit., p. 14.

${ }^{70}$ USDA, "Memorandum for Employees of Rubber Plant Investigations, Progress Report N ${ }^{\circ} 11$ (Newsletter), 01-10-1941", Hunt Institute for Botanical Documentation (Carnegie Mellon University), F. Wilson Popenoe family papers, 1882-1975, Box 31, Folder 21. Disponible en http://huntbot.org/findingaids/0204/204_Popenoe_Bx31FF21r.pdf [fecha de consulta: 13 de julio de 2020]. 


\section{Las redes público-privadas en las principales sedes del programa regional: En busca de semillas resistentes y productivas}

Uno de los objetivos de las exploraciones realizadas por el personal del USDA en 1940 fue definir el mapa territorial del programa, estableciendo acuerdos para la instalación de centros responsables de cada una de las operaciones y sentando las bases para el flujo regional de información y material genético (Fig. 3). Por supuesto, no todos los países participaron en pie de igualdad en estas operaciones, pues la localización de los centros respondía tanto a consideraciones ambientales como a la acumulación previa de conocimiento, a los intereses y la colaboración de las grandes empresas estadounidenses, y a las respuestas de los respectivos gobiernos latinoamericanos.

Brasil y Costa Rica fueron las principales sedes del programa regional en lo que se refiere a las actividades de investigación. La elección de estos países respondía a consideraciones estratégicas, vinculadas con la presencia de Ford y Goodyear, y a la incidencia del mal sudamericano de la hoja en ambos territorios, que permitía probar la resistencia de clones asiáticos, de híbridos y de especímenes silvestres provenientes de los diversos países que integraban el Amazonas (Brasil, Perú, Colombia, Ecuador y Venezuela $)^{71}$. En buena medida, el programa apuntaba a complementar y expandir las investigaciones que venían desarrollando las empresas desde mediados de la década de 1930 y a formalizar la cooperación que, de hecho, habían establecido.

Sin embargo, para 1940, Ford había empezado a perder interés en su emprendimiento. Entre 1940 y 1941, luego de plantar alrededor de tres millones de árboles y combatir múltiples plagas de insectos en Belterra, una nueva epidemia del mal sudamericano de la hoja golpeó las plantaciones. Cuando el equipo de expertos del USDA llegó a Brasil, Fordlandia y Belterra se convirtieron en la práctica en subsidiarias del gobierno estadounidense: científicos del USDA se establecieron allí para estudiar las técnicas del injerto de copa y fertilización cruzada, y para enviar muestras a las estaciones de investigación tropical de Estados Unidos y de la zona del canal de Panamá72. En octubre de 1940, el USDA y el Ministerio de Agricultura de Brasil firmaron un acuerdo para establecer en el recientemente creado Instituto Agronómico do Norte (IAN) de Belém una de las sedes del programa regional ${ }^{73}$. El USDA y el IAN obtuvieron permiso de Ford para utilizar

\footnotetext{
${ }^{71}$ En especial, las condiciones climáticas en Costa Rica tenían la ventaja de permitir la difusión de la enfermedad todos los años a partir de alguna fuente mínima de inoculación natural, que resultaba más segura que la inoculación artificial y permitía realizar testeos de resistencia en menor tiempo. Rands \& Polhamus, op. cit., pp. 40-41.

${ }^{72}$ Grandin, op. cit., pp. 316-317.

${ }^{73}$ La creación del IAN, en 1939, fue parte de una política más amplia de promoción de la investigación y desarrollo agrícola en el ámbito nacional, iniciada en 1938 con la creación de nuevas agencias dentro del Ministerio de Agricultura, como el Centro Nacional de Ensino e Pesquisa Agrícola y una serie de institutos agrícolas regionales similares al IAN que, entre 1943 y 1946, se instalaron en los estados de Pernambuco, Minas Gerais, Rio Grande do Sul y Bahía. El IAN, estuvo bajo la dirección de Filisberto Camargo, que entre 1919 y 1920 había realizado estudios de posgrado sobre cultivo de frutas tropicales en la Universidad de Florida. Desde 1941, el IAN también contó con un grupo de expertos en citología, genética y horticultura del Instituto Agronómico de Campinas. Dominichi Miranda de Sá \& André F. Cándido da Silva, “The Brazilian Amazon, the World's Breadbasket: Science, Agriculture and Ecology at the Agronomic Institute of the North in the 1940s and 1950s", en Revista de História, n. ${ }^{\circ}$ 179, São Paulo, 2019, pp. 1-25.
} 
sus selecciones resistentes a cambio de complementar el programa de cruzamiento que la empresa venía llevando a cabo desde 1939 y colaborar en el proceso de selección. Entre 1942 y 1944, el IAN, con la colaboración de Lawrence A. Beery, Jr. -otro exempleado de Goodyear ahora asignado por el USDA a Brasil- complementaría el programa de cruzamiento de Ford, desarrollando un proyecto de polinización manual a gran escala en la plantación de Belterra y enviando los híbridos para su testeo en los viveros del IAN ${ }^{74}$. Según un informe del USDA, para 1944 se habían realizado en Brasil 53880 polinizaciones manuales para producir 161 combinaciones diferentes y veinte retrocruzamientos con cepas brasileñas y asiáticas ${ }^{75}$. Aunque la Ford Motors Co. abandonó sus plantaciones en enero de 1946, Charles H. Townsend continuaría colaborando con el programa de cruzamiento en Brasil ${ }^{76}$.

Mientras que la principal contribución de Ford eran las selecciones resistentes, la colaboración de Goodyear era crucial no solo por su expertise de veinte años en cultivo y mejoramiento de Hevea, sino, también, por sus clones de alto rendimiento. Entre fines de 1940 y fines de 1941 (poco antes de Pearl Harbor) Estados Unidos logró trasladar a América Latina tres cargamentos con plántulas injertadas con distintas cepas de clones de alta productividad provenientes de Filipinas (Fig. 4). A fines de 1941 también se sumó Firestone, que venía evaluando la posibilidad de establecer una plantación en América Latina, y aportó dos cargamentos de semillas y esquejes de sus plantaciones en Liberia $^{77}$. Como veremos, Firestone también fue un importante "semillero" de expertos enviados a diversos países de América Latina para realizar tareas de exploración o para iniciar los proyectos experimentales.

${ }^{74}$ Rands \& Polhamus, op. cit., p. 32; Dean, op. cit., p. 91.

${ }^{75}$ Robert M. Salter, "Report of the Chief of the Bureau of Plant Industry, Soils and Agricultural Engineering, Agricultural Research Administration", in Annual Reports of the Department of Agriculture, Washington D.C., 1944, pp. 27-28. Disponible en https://books.google.com.ar/books?id=SAZ16dSKcPUC\&pg=RA2PA1\&lpg=RA2-PA1\&dq=Robert + M. + Salter,+ Report + of + the + Chief + of + the + Bureau + of + Plant + Indust ry, + Soils + and + Agricultural + Engineering, + Agricultural+Research + Administration. + Annual + Reports + of + the + Department + of + Agriculture, $+1944 \&$ source $=$ bl\&ots $=$ Z7p9ptyOdO\&sig $=$ ACfU3U369k7X3ju 8 8f3yM7hnS0VTPYHneA\&hl=es\&sa=X\&ved=2ahUKEwjI3e7jhNXtAhWRHrkGHaBpBPcQ6AEwAHoEC AEQAg\#v=onepage \&q=Robert $\% 20$ M. $\% 20$ Salter $\% 2$ C $\% 20$ Report $\% 20$ of $\% 20$ the $\% 20$ Chief $\% 20$ of $\% 20$ the $\% 20$ Bureau \%20of\%20Plant\%20Industry\%2C\%20Soils\%20and\%20Agricultural\%20Engineering $\% 2 \mathrm{C} \% 20$ Agricultural\%20Research\%20Administration.\%20Annual\%20Reports\%20of\%20the\%20Department $\% 20$ of $\% 20$ Agriculture $\% 2 \mathrm{C} \% 201944 \& \mathrm{f}=$ false [fecha de consulta: 25 de marzo de 2020].

${ }^{76}$ A. Clément-Demange, P. Priyadarshan, T. Hoa \& P. Venkatachalan, "Hevea Rubber Breeding and Genetics", in Jules Janick (ed.), Plant Breeding Reviews, Hovoken, Wiley, 2007, vol. 29, pp. 177-283.

${ }^{77}$ Dean, op. cit., p. 91; Loren G. Polhamus, "War Speeds the Rubber Project", in Agriculture in the Americas, vol. II, No. 2, Washington D.C., 1942, pp. 30-31. Disponible en https://hdl.handle.net/2027/umn.31 951d00045071j?urlappend=\%3Bseq=265 [fecha de consulta: 10 de julio de 2020]. 
Figura 4

Bombarderos del ejército estadounidense

trasladando semillas filipinas de caucho desde Panamá a Belém,

Brasil (1941)

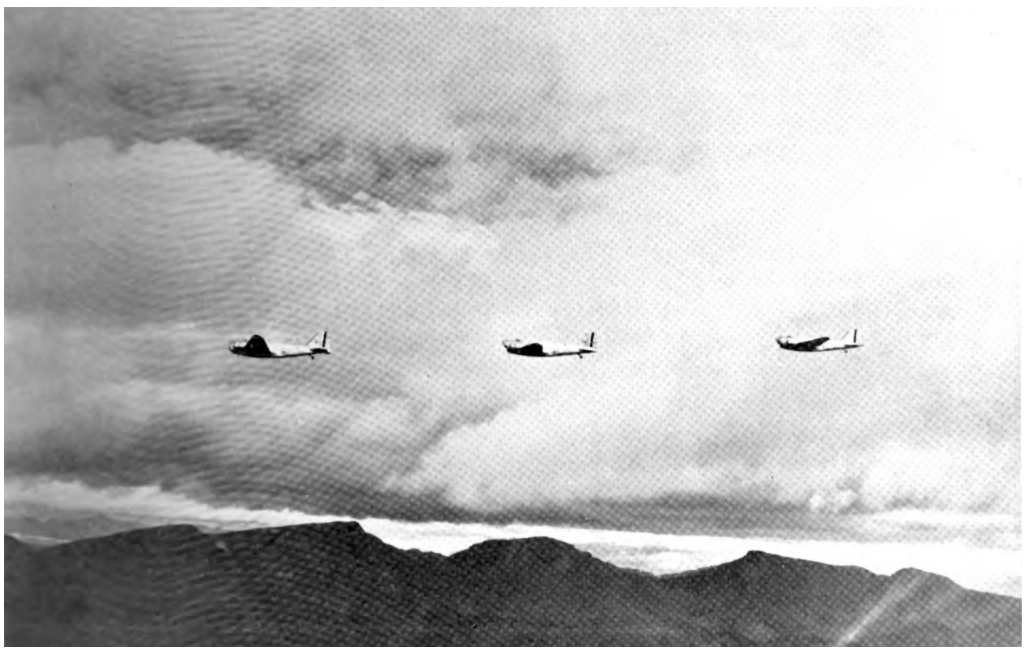

Fuente: Brandes, op. cit.

A su vez, en junio de 1941 el USDA firmó un acuerdo con el gobierno costarricense para instalar en Turrialba la sede central del programa regional, conducida por personal estadounidense y financiada por la Division of Rubber Plant Investigations del USDA ${ }^{78}$. Cuando se inició el programa del USDA, el patólogo Michael H. Langford, que trabajaba en la plantación de Goodyear en el lago Gatún (Panamá), fue transferido a Turrialba para dirigir, junto con los patólogos Theodore J. Grant y Ernest P. Imle, los estudios sobre la enfermedad y los trabajos de selección. En Turrialba se experimentó con el uso de diversos fungicidas para controlar la enfermedad en los viveros, se estableció un museo de clones y se desarrolló un esquema de clasificación de la susceptibilidad ${ }^{79}$. Allí se evaluó la susceptibilidad de las selecciones resistentes e híbridos de Ford, los clones de alto rendimiento de Firestone y Goodyear, especímenes de la plantación experimental de Goodrich en República Dominicana -basada en semillas recolectadas en Mato Grosso, Brasil- y selecciones silvestres enviadas desde diversos distritos del Amazonas. Algunos de los testeos, incluso, se hicieron de manera simultánea y comparativa con el IAN de Belém ${ }^{80}$. En 1947, Walter Bangham, exdirector del Departamento de Investigación

\footnotetext{
${ }^{78}$ La estación se asentó en un terreno de treinta y dos hectáreas cedido por el gobierno costarricense, en el que se estableció la colección permanente de clones y viveros para la evaluación y selección de progenies.

${ }^{79}$ Rands \& Polhamus, op. cit., p. 40.

${ }^{80}$ USDA, "Memorandum for Employees of Rubber Plant Investigations, Progress Report N ${ }^{0} 11 \ldots .$, op. cit.; USDA, "Memorandum for Employees of Rubber Plant Investigations, Progress Report $\mathrm{N}^{\circ} 12$ (Newsletter), 05-11-1941", Hunt Institute for Botanical Documentation (Carnegie Mellon University), F. Wilson Popenoe family papers, 1882-1975, Box, 31, Folder 21. Disponible en http://huntbot.org/findingaids /0204/204_Popenoe_Bx31FF21r.pdf [fecha de consulta: 13 de julio de 2020].
} 
sobre plantas de Goodyear, afirmaba que los doctores E. W. Brandes y Robert Rands, del centro del BPI en Beltsville, y el personal de Turrialba, bajo la dirección de Imle, se ocuparon de la distribución del material para plantación y fueron el centro de coordinación de la información originada en cualquier localidad del programa ${ }^{81}$.

Además de Brasil y Costa Rica, Honduras y Haití también tuvieron un papel protagónico: el programa requería estaciones localizadas en zonas libres de la enfermedad, donde pudieran ejecutarse las fases del cruzamiento que involucraban material susceptible, además de recibirse y multiplicarse los clones asiáticos para su posterior distribución al resto de los países que integraban el programa (Brasil, Perú, Colombia, Ecuador, Venezuela, Guatemala, México, Nicaragua y El Salvador) ${ }^{82}$. En sus inicios, Haití y Honduras fueron identificadas como lugares propicios para estas actividades, y poco más tarde se incorporaría Guatemala ${ }^{83}$. Allí se enviarían también las selecciones aparentemente resistentes de Ford y las selecciones silvestres provenientes de diversos países (Perú, Venezuela y Brasil) previa desinfección y cuarentena realizada en Arlington Farm (Washington), donde también se realizaban estudios fisiológicos. La idea era que, si alguno de esos materiales pasaba con éxito las pruebas de resistencia, los expertos estadounidenses estarían en una posición más ventajosa para su rápida multiplicación con fines productivos o para su utilización en el programa de cruzamiento ${ }^{84}$.

En especial, la insularidad de Haití -donde además se había acordado la creación de una corporación para promover cultivos estratégicos- ofrecía una protección natural $\mathrm{y}$, al igual que en Honduras, sus antiguas plantaciones no evidenciaban la presencia del hongo $^{85}$. En 1941 comenzó la instalación de la segunda estación regional del USDA en Marefranc (la primera fue en Turrialba), dirigida por personal estadounidense y asentada en un terreno provisto por el gobierno haitiano. Entre 1942 y 1952 se establecieron allí jardines de cruzamiento y de producción de semillas ${ }^{86}$. Asimismo, la estación experimental y el jardín de introducción de plantas de la UFCo. en el Valle de Lancetilla (Honduras) se incorporó como una de las sedes del programa bajo la dirección de Edward T. Stanwood, quien había trabajado en los Jardines de Experimentación de Summit en la zona del canal de Panamá ${ }^{87}$. El acuerdo con la compañía, también incluía el establecimiento de plantaciones experimentales en zonas con diferentes suelos y condiciones climáticas, por lo que esta estableció un vivero en Almirante (Panamá) y una plantación experimental en el Valle de Motagua (Guatemala) ${ }^{88}$. La expectativa era que,

\footnotetext{
${ }^{81}$ Bangham, op. cit., p. 221.

${ }^{82}$ Rands \& Polhamus, op. cit., pp. 19-20.

${ }^{83}$ También se realizaron cruzamientos que involucraban material susceptible en Coconut Grove, Florida, Estados Unidos.

${ }^{84}$ USDA, Memorandum for Employees of Rubber Plant Investigations, Progress Report No. 11..., op. cit.

${ }^{85}$ Lo mismo se había constatado en la plantación experimental de Goodrich en República Dominicana.

${ }^{86}$ Rands \& Polhamus, op. cit., p. 54.

${ }^{87}$ Stanwood, op. cit.

${ }^{88}$ USDA, "Memorandum for Employees of Rubber Plant Investigations, Progress Report N 11...”, op. cit.; Rands \& Polhamus, op. cit., p. 51; Carta de E. W. Brandes a W. E. Thurnbull, 26 de diciembre de 1940, Hunt Institute for Botanical Documentation (Carnegie Mellon University), F. Wilson Popenoe family papers, 1882-1975, Box 31, Folder 21. Disponible en http://huntbot.org/findingaids/0204/204_Popenoe_ Bx31FF21r.pdf [fecha de consulta: 13 de julio de 2020]. En los inicios del programa la UFCo también fue un informante clave, pues sus técnicos aportaron mapas de suelos y registros climáticos de los países en los que operaba, brindaron asesoramiento sobre regiones potencialmente adecuadas para el desarrollo del cultivo
} 
si el cultivo de Hevea lograba desarrollarse, la empresa podría recuperar las tierras abandonadas debido a la epidemia de sigatoka que había afectado muchas plantaciones bananeras en América Central desde la década de $1930^{89}$.

Guatemala fue el tercer país seleccionado para el establecimiento de una estación experimental regional del USDA con funciones, en sus inicios, similares a las de Haití y Honduras. Luego del acuerdo firmado con el gobierno guatemalteco en junio de 1941, comenzó la instalación de la estación de multiplicación y distribución en Cuyotenango. En 1944, Lawrence A. Beery, que había colaborado con el programa de cruzamiento en Brasil, fue transferido a Centroamérica para liderar los proyectos de Guatemala, El Salvador, Honduras y Nicaragua. Entre otras actividades, Lawrence Beery completó el establecimiento de los primeros jardines de cruzamiento. Sin embargo, la inesperada aparición del mal de la hoja al norte de Costa Rica, primero en México (1946) y luego en la costa oeste de Guatemala y en Honduras (1948), demoró el proyecto de cruzamiento en estos dos países ${ }^{90}$.

\section{Exploración del territorio:}

\section{Los botánicos, el mapa taxonómico y la circulación de germoplasma}

La disponibilidad de un amplio territorio para explorar explica, en buena medida, el optimismo con el que los expertos del USDA se lanzaron al programa: si las plantaciones del Sudeste Asiático, originadas en una variedad local de una sola especie (la Hevea brasiliensis de la región de Tapajoz) habían prosperado, era casi imposible que, con acceso a material genético tan diverso, el programa en América Latina fracasara ${ }^{91}$. Tanto las expediciones realizadas en la década de 1920 por el USDA y el USDC, como las recolecciones y los estudios del personal de las plantaciones de Ford habían sugerido una gran variación de resistencia entre diversas especies y se tenía conocimiento acerca de las diferencias en la cantidad y calidad del látex que podía extraerse. Así, desde el inicio del programa, la producción y centralización de información sobre especies y variedades silvestres se planteó como uno de los principales objetivos. En mayo de 1941, el director de la OFAR afirmaba: "Si se van a desarrollar nuevos cultivos es imperativo que sepamos qué especies están disponibles [...]. Estados Unidos debe ser, ciertamente, el centro de conocimiento de todas las plantas del hemisferio occidental y es nuestra responsabilidad alcanzar esta posición"92.

\footnotetext{
y funcionaron como facilitadores de los vínculos con autoridades nacionales y plantadores (en particular, en Guatemala). Carta de Wilson Popenoe a W. E. Thurnbull, 12 de agosto de 1940, Hunt Institute for Botanical Documentation (Carnegie Mellon University), F. Wilson Popenoe family papers, 1882-1975, Box 31, Folder 21. Disponible en http://huntbot.org/findingaids/0204/204_Popenoe_Bx31FF21r.pdf [fecha de consulta: 13 de julio de 2020]; Carta de Wilson Popenoe a W. E. Thurnbull, 7 de noviembre de 1940, Hunt Institute for Botanical Documentation (Carnegie Mellon University), F. Wilson Popenoe family papers, 1882-1975, Box 31, Folder 21. Disponible en http://huntbot.org/findingaids/0204/204_Popenoe_Bx31FF21r.pdf [fecha de consulta: 13 de julio de 2020]; Carta de E. W. Brandes a W. E. Thurnbull, op. cit.

${ }^{89}$ Carta de Wilson Popenoe a W. E. Thurnbull, 4 de octubre de 1940, Hunt Institute for Botanical Documentation (Carnegie Mellon University), F. Wilson Popenoe family papers, 1882-1975, Box 31, Folder 21. Disponible en http://huntbot.org/findingaids/0204/204_Popenoe_Bx31FF21r.pdf [fecha de consulta: 13 de julio de 2020].

${ }^{90}$ Rands \& Polhamus, op. cit., pp. 51-52.

${ }^{91}$ Davis, op. cit.

${ }^{92}$ Earl N. Bressman, "As the Hemisphere Changes", in Agriculture in the Americas, Washington D.C., March 1941, p. 4. Disponible en https://hdl.handle.net/2027/umn.31951d00045071j?urlappend=\%3Bseq=33 [fecha de consulta: 13 de julio de 2020].
} 
En ese marco, los equipos de expertos que recorrieron América Latina entre 1940 y 1941 también tuvieron la misión de recolectar semillas y esquejes de diversas especies y variedades regionales para plantarlas en los respectivos países y enviarlas a las estaciones centrales de investigación ${ }^{93}$. El propósito era no solo testear primero su resistencia y luego su productividad, sino, también, tener variedades adaptables a diversos ambientes que pudieran luego utilizarse en países que no poseían este recurso natural (Fig. 5).

Figura 5

Un miembro del equipo de exploración de caucho en pleno trabajo (1941)

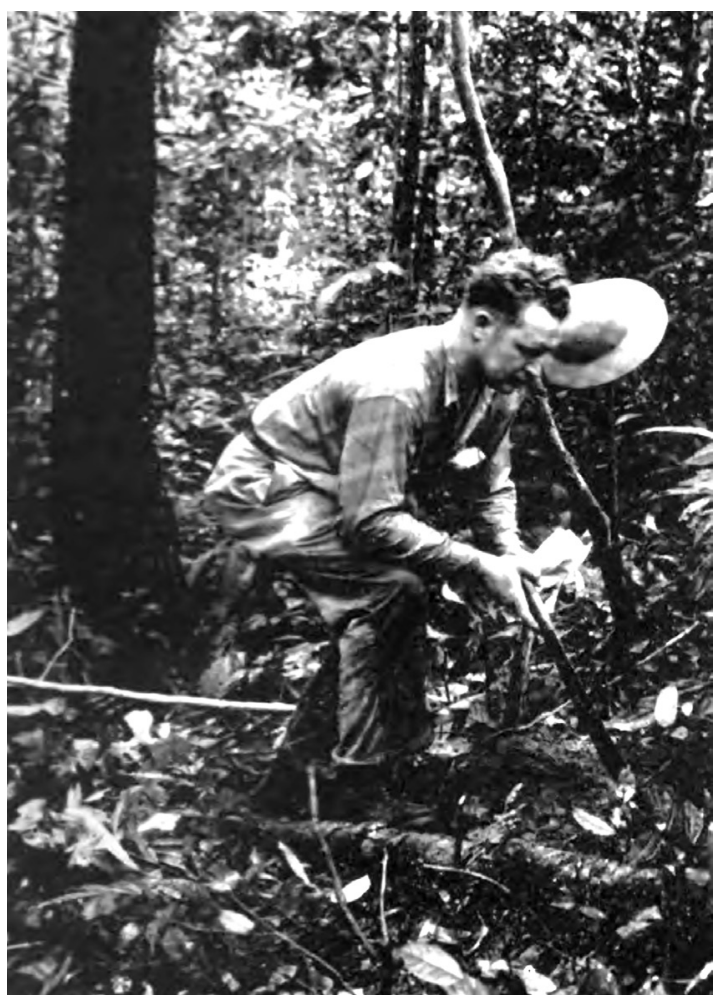

Fuente: Blandin, op. cit.

Los acuerdos firmados con los países que integraban el Valle del Amazonas (Brasil, sobre todo, pero también Ecuador, Perú y Colombia) eran, por lo tanto, una pieza clave para la buena marcha del programa, pues regulaban el intercambio de material. Por

\footnotetext{
${ }_{93}$ Brandes, "Rubber on the...", op. cit., p. 7; USDA, "Memorandum for Employees of Rubber Plant Investigations, Progress Report N 9 (Newsletter), 10-04-1941", Hunt Institute for Botanical Documentation (Carnegie Mellon University), F. Wilson Popenoe family papers, 1882-1975, Box 31, Folder 21. Disponible en http://huntbot.org/findingaids/0204/204_Popenoe_Bx31FF21r.pdf [fecha de consulta: 13 de julio de 2020].
} 
ejemplo, el acuerdo firmado entre Colombia y el BPI en enero de 1941 establecía que el gobierno colombiano se comprometía a recolectar semillas de árboles de Hevea nativos, plantarlas en jardines de testeo nacionales y enviar muestras a estaciones designadas por el BPI para ensayos de resistencia y obtención de selecciones, que luego fueran plantadas en estaciones colombianas para su propagación y uso. Asimismo, el gobierno colombiano se comprometía a prohibir la distribución de material provisto o desarrollado en el marco del acuerdo, a empresas o gobiernos de otros países, excepto aquellos gobiernos que ofrecieran reciprocidad. En contrapartida, el BPI asumía la responsabilidad de enviar especialistas para colaborar con el proceso de experimentación ${ }^{94}$.

Sin embargo, los expertos del USDA todavía sabían poco acerca de la clasificación de este género, debido a que el patrón disperso de distribución y las condiciones adversas del Amazonas para el desplazamiento habían dejado amplios terrenos sin explorar. A partir de 1942, por lo tanto, el USDA envió botánicos para explorar de manera más sistemática los territorios amazónicos de Brasil, Colombia y Perú y llevar a cabo estudios citogeográficos, taxonómicos y ecológicos, que permitieran una clasificación más precisa. Entre 1942 y 1944, John T. Baldwin Jr. llevó a cabo un estudio citogeográfico en Brasil, a partir del cual también recolectó material que fue enviado al IAN. Entre 1943 y 1945 el trabajo de exploración y recolección en Colombia fue puesto en manos de Richard E. Schultes, que luego continuó sus exploraciones en Brasil. Entre 1943 y 1947 Russel Seibert realizó un estudio taxonómico en el que mapeó las seis variedades y especies de Perú. Todos ellos hicieron aportes relevantes al conocimiento del género partiendo de la clasificación más confiable que había para la época, que era la que Adolpho Ducke -entomólogo y botánico italiano radicado en Brasil desde fines del siglo XIX- había propuesto a mediados de la década de $1930^{95}$. Asimismo, trabajaron en la identificación de especímenes potencialmente resistentes y productivos que enviaron a las estaciones del programa.

El trabajo de exploración y clasificación tuvo consecuencias en la apertura de nuevas líneas de experimentación. En tanto algunas de las selecciones provenientes de Madre de Dios (Perú) presentaban altos niveles de resistencia al hongo, en 1948 se decidió estudiar sus características en condiciones uniformes de cultivo en Costa Rica y en Guatemala. El gobierno costarricense, además del terreno de treinta y dos hectáreas de Turrialba, había adquirido un terreno de setecientas sesenta y nueve hectáreas para el establecimiento de la subestación Los Diamantes, donde el USDA realizaría experimentos de campo a gran escala para testear el vigor y la productividad de los árboles, y para estudiar la viabilidad de sistemas de plantación intercalada con cultivos alimenticios o comerciales ${ }^{96}$. Allí se sembraron pequeñas poblaciones de plántulas provenientes de Madre de Dios. A su vez, Firestone Plantations Co. firmó un acuerdo con el BPI para

${ }^{94}$ O. D. Hargis, E. C. Stakman, K. E. Johnson, C. D. La Rue, H. Sorensen \& W. G. Whaley, Cooperative InterAmerican Plantation Rubber Development. Colombia, USDA, Washington D.C., 1946, pp. 53-54. Disponible en https://books.google.com.ar/books?id=yKEW23bhCnYC\&printsec=frontcover\&hl=es\&source=gbs_ge_su mmary_r\&cad $=0 \# \mathrm{v}=$ onepage\&q\&f$=$ false [fecha de consulta: 20 de mayo de 2020].

${ }^{95}$ Richard E. Schultes, "The History of Taxonomic Studies in Hevea”, in Botanical Review, vol. 36, No. 3, New York, 1970, pp. 197-276; Rands \& Polhamus, op. cit., pp. 16-17.

${ }^{96}$ Rands \& Polhamus, op. cit., pp. 40-41. 
el establecimiento de una plantación experimental en Guatemala con colecciones de semillas provistas por el Ministerio de Agricultura de Perú. El objetivo del proyecto era desarrollar clones resistentes y determinar la adaptabilidad a Guatemala de híbridos producidos en ese país o en otros países del hemisferio occidental. Coincidente con esto, en 1951 la estación de Cuyotenango (Guatemala), bajo la dirección del genetista estadounidense J. E. Shrum, se incorporó por fin al programa de cruzamiento. Para entonces, el genetista C.N. Hittle coordinaba las distintas fases del cruzamiento en Costa Rica, Haití y Guatemala ${ }^{97}$.

Hacia el final del programa, el USDA no solo había logrado una identificación y clasificación más precisa de especies y variedades silvestres, sino que, además, había reunido una importante cantidad de información derivada de las pruebas de resistencia y rendimiento de especies, variedades e híbridos. En 1951, un informe del USDA que reseñaba el programa de cruzamiento afirmaba: "La disponibilidad de una amplia variedad de material genético completamente dentro de los Estados Unidos, y completamente bajo su control, ofrece la oportunidad para estudios básicos sobre la genética de las plantas de caucho y el desarrollo de híbridos para su testeo más extensivo en áreas de producción de caucho de Sudamérica y Centroamérica"98.

Agrónomos y agricultores:

Transferencia de técnicas de cultivo y modelos productivos

Los estudios realizados en Turrialba y Belém también estaban vinculados con la estrategia de mediano plazo, que consistía en utilizar la planta de tres componentes. Esta planta se había diseñado como respuesta experimental a la ya señalada epidemia del mal sudamericano de la hoja, que afectó las plantaciones de Ford en 1935. En ese momento, los injertos en raigones vigorosos se practicaban desde hacía quince años en las colonias holandesas, pero los injertos de copa solo se habían realizado experimentalmente en Java a mediados de la década de 1920. Con el advenimiento de la epidemia, James Weir recomendó utilizar esta técnica a escala experimental en Fordlandia (1936) y Belterra (1937), injertando cepas de Hevea guianensis y otras especies que habían sobrevivido. Cuando se produjo la epidemia de 1940-1941, la técnica se aplicó a gran escala ${ }^{99}$. Ese fue el origen del árbol de tres componentes que los expertos estadounidenses esperaban difundir como cultivo transitorio a América Latina (Fig. 6). La implementación de esta segunda línea del programa suponía, entre otras cosas, una transferencia y estandarización de prácticas agrícolas entre agrónomos y agricultores de diversos países.

\footnotetext{
${ }^{97}$ Rands \& Polhamus, op. cit., pp. 50-51 y 53-55.

${ }^{98}$ USDA, Research and..., op. cit., p. 1429.

${ }^{99}$ Davis, op. cit., p. 627.
} 
Figura 6

El Dr. Stackman, líder del equipo de exploración a Perú, Ecuador y Colombia, y el Dr. R. D. Rands, ambos del USDA, inspeccionan plántulas de Hevea injertadas (1941)

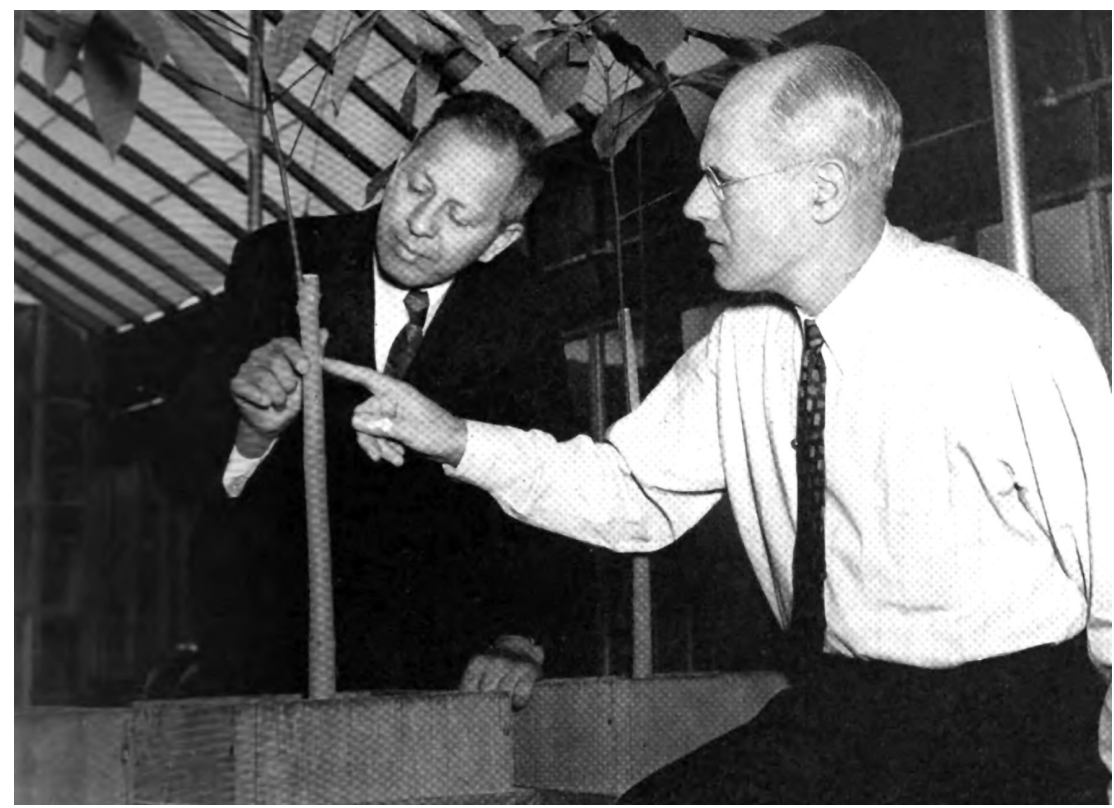

Fuente: Edgar R. Burkland, "Rubber grows up", in Agriculture in the Americas, Washington D. C., March 1941, p. 13. Disponible en https://hdl.handle.net/2027/umn.31951d00045071j?urlappend= $\% 3$ Bseq $=45$ [fecha de consulta: 6 de septiembre de 2021].

Junto con las técnicas experimentadas o practicadas en el Sudeste Asiático, los expertos estadounidenses esperaban poder transferir también la organización socioeconómica de la producción. Se esperaba que las plántulas de tres componentes preparadas en los viveros de las estaciones experimentales se transfirieran luego a plantaciones -públicas o privadas- que tuvieran un efecto de demostración sobre pequeños productores, que podrían intercalar el caucho con cultivos alimenticios o comerciales. Como explicara John J. Blandin, ese era el modelo que se había desarrollado en el Sudeste Asiático, donde las grandes plantaciones cumplían un papel "educativo" para los pequeños productores, que producían el $50 \%$ del caucho ${ }^{100}$. Aunque E. W. Brandes acordaba en transferir ese modelo, señalaba que en los países latinoamericanos no había tantas plantaciones, por lo que la expansión del cultivo requeriría una activa participación de sus gobiernos para instalar viveros y plantaciones experimentales, para estimular la producción a escala familiar y para realizar trabajo de extensión ${ }^{101}$. De hecho, dado que en el Sudeste Asiático los pequeños productores combinaban diversos cultivos comerciales

\footnotetext{
${ }^{100}$ Blandin, op. cit., p. 7.

${ }^{101}$ Brandes, "Rubber on the...", op. cit., p. 10.
} 
con cultivos alimenticios y la cría de ganado en pequeña escala, la estación de Costa Rica llevó a cabo experimentos para intercalar ambos tipos de cultivos ${ }^{102}$.

En este marco, las expediciones realizadas por el personal del USDA desde 1940 tuvieron como objetivo no solo recolectar semillas y plantas o identificar especies, variedades y enfermedades, sino, también, mapear zonas adecuadas para la instalación de viveros o plantaciones, basándose en criterios como el clima, el suelo, la infraestructura (sobre todo las carreteras, que aseguraban la accesibilidad) y las características de la población potencialmente productora (existencia de pequeños productores o proyectos de colonización). En efecto, en esas expediciones se recolectó una amplia variedad de información agrícola y económica, como el rango de las propiedades de tierra, los cultivos tropicales, las tarifas de almacenamiento en los puertos más cercanos, las condiciones de salud, la tasa de salarios de la población y hasta aspectos prácticos involucrados en las relaciones de los patrocinados gubernamentales departamentales y federales ${ }^{103}$.

Esta línea del programa involucraba, por lo tanto, tres etapas. La primera era la preparación de viveros y centros de multiplicación y distribución nacionales: se recibían los clones asiáticos (susceptibles) y las selecciones resistentes, se entrenaba al personal en las técnicas de germinación de semillas, de reproducción, de injertos de base y de copa y de control de enfermedades. Había una estrecha colaboración entre los expertos estadounidenses y los agrónomos a cargo en cada país, muchos de los cuales eran enviados a la estación regional de Costa Rica y a la estación de propagación de Honduras para conocer las diversas operaciones involucradas en el programa ${ }^{104}$. De hecho, la estación regional de Costa Rica, adyacente al IICA, representó un papel importante en la formación de especialistas en caucho: desde su instalación hasta 1953 se formaron allí diecisiete estudiantes o agrónomos latinoamericanos con estadías de un mes a un año.

La segunda etapa consistía en el establecimiento de plantaciones públicas o privadas, que no solo resultaban útiles como modelo para los pequeños productores y para realizar investigaciones sobre la tasa de crecimiento y la productividad de los árboles. Se trataba, en principio, de plantaciones experimentales, pues los expertos tenían aún más incertidumbres que certezas. Se desconocía la adaptabilidad de los clones asiáticos a las diversas condiciones locales y los efectos de los injertos de copa en el crecimiento, cantidad y calidad del látex, por lo que era necesario comparar diferentes clones asiáticos y combinaciones de injertos en cada lugar para identificar los más adecuados al ambiente local ${ }^{105}$.

${ }^{102}$ Richard Schultes \& Alfonso Uribe Henao, "The Future of Rubber Growing in Colombia", in Agriculture in the Americas, vol. VII, Nos. 10-11, Washington D.C., 1947, p. 128. Disponible en https://hdl.handle.net/2027/uiug .30112045346175 ? urlappend=\%3Bseq=349 [fecha de consulta: 20 de junio de 2020]; Rands \& Polhamus, op. cit.

${ }^{103}$ Brandes, "Rubber on the...", op. cit., p. 7.

${ }^{104}$ C. D. La Rue, T. S. Grant, R. E. Stadelman, T. D. Mallery, K. E. Johnson \& W. G. Whaley, Cooperative Inter-American Plantation Rubber Development. México, Washington D.C., USDA, 1946. Disponible en https://books.google.com.ar/books?id=yKEW23bhCnYC\&printsec=frontcover\&hl=es\&source=gbs_ge_sum mary_r\&cad=0\#v=onepage \&q\&f=false [fecha de consulta: 20 de mayo de 2020]; Stanwood, op. cit.; Carta de R. D. Rands a Wilson Popenoe, 17 de septiembre de 1941, Hunt Institute for Botanical Documentation (Carnegie Mellon University), F. Wilson Popenoe family papers, 1882-1975, Box 31, Folder 21. Disponible en http://huntbot.org/findingaids/0204/204_Popenoe_Bx31FF21r.pdf [fecha de consulta: 13 de julio de 2020].

${ }^{105}$ La Rue, Grant, Stadelman, Manifold, Mallery, O’Donnal, Johnson \& Whaley, op. cit.; Hans G. Sorensen, "Crown Budding for Healthy Hevea", in Agriculture in the Americas, vol. II, No. 10, Washington D. C., 
Tanto la primera como la segunda etapa estuvieron bajo la supervisión de los expertos del USDA, quienes decidían qué clones, especies o variedades se plantaban o testeaban en cada país. Este papel de liderazgo fue más explícito en aquellos países en los que se establecieron estaciones experimentales. Según el subdirector de Relaciones Latinoamericanas de la OFAR, el convenio con Perú, por ejemplo, establecía que el USDA proveería los científicos (un director de la estación, un genetista de plantas y especialista en fitomejoramiento, un especialista en cría de animales, un especialista en caucho y un experto en extensión agrícola), mientras que el gobierno peruano proporcionaría las instalaciones, las tierras y un agrónomo propio por cada agrónomo estadounidense ${ }^{106}$. En ese marco, especialistas estadounidenses fueron designados jefes de los diversos departamentos de la estación, secundados por agrónomos peruanos. Como experto en caucho a cargo del Departamento Forestal de Tingo María fue enviado Rolland Lorenz que, al igual que el director de la estación de Ecuador (Lee Haines) y los encargados del proyecto en Haití (Franklin Bradshaw y Montgomery P. Copeland), había trabajado para Firestone en África ${ }^{107}$.

La tercera etapa consistía en la distribución de material para plantación entre los pequeños productores, acompañada del trabajo de extensión. Las estaciones experimentales tenían el propósito de investigar, estandarizar y difundir las prácticas de cultivo, de sensibilizar a la población con cultivos cuyos beneficios solo obtendrían en el largo plazo (como en el caso de la Hevea) ${ }^{108}$ y de garantizar la subsistencia de los pequeños productores, pues nadie sembraría cultivos comerciales si no tenía para alimentarse o si no gozaba de buena salud ${ }^{109}$. En ese marco, desde 1943 la OFAR envió expertos para realizar estudios sociológicos de la población cercana a las estaciones experimentales (primero a Perú, luego a Ecuador y, por último, a El Salvador y Costa Rica), que sirvieran como punto de partida para un programa de extensión. En 1945, una agrónoma de la OFAR, Dorothy Chapman, realizó un viaje por Guatemala, Perú, Ecuador, El Salvador y México, con el propósito de recoger material necesario para la publicación de folletos instructivos destinados a los productores. Reconocía, de todos modos, que "los materiales escritos son, en el mejor de los casos, ayudas complementarias a la asistencia del especialista full-time formado en extensión" "110. Nicolás Cuvi relata que la extensión se volvió una de

1942, pp. 191-193. Disponible en https://hdl.handle.net/2027/umn.31951d00045071j?urlappend=\%3Bs eq=427 [fecha de consulta: 17 de julio de 2020]; Rands \& Polhamus, op. cit., p. 10.

${ }^{106}$ Ross E. Moore, "Tingo María", in Agriculture in the Americas, vol. III, No. 6, Washington D.C., 1943, p. 107. Disponible en https://hdl.handle.net/2027/umn.31951d00045071j?urlappend $=\% 3$ Bseq $=593$ [fecha de consulta: 4 de agosto de 2020]

${ }^{107}$ USDA, "Memorandum for Employees of Rubber Plant Investigations, Progress Report № 9...", op. cit.; Cuvi, "Las semillas...", op. cit.

${ }^{108}$ Por ejemplo, el experto en extensión enviado a Perú, advertía con cierta preocupación que los colonos de Tingo María tenían preferencia por el cultivo de coca, lo que planteaba un problema para el desarrollo de cultivos complementarios estratégicos. Charles P. Loomis, "Extension Work at Tingo Maria", in Agriculture in the Americas, vol. IV, No. 2, Washington D.C., 1944, pp. 23-26 \& 36. Disponible en https://hdl.handle. net/2027/umn.31951d00045071j?urlappend=\%3Bseq=755 [fecha de consulta: 12 de mayo de 2020].

${ }^{109}$ Cuvi, "Las semillas...", op. cit.

${ }^{110}$ Dorothy E. Chapman, "Agricultural Extension Project in the Other Americas", in Agriculture in the Americas, vol. VI, No. 2, Washington D.C., 1946, p. 38. Disponible en https://hdl.handle.net/2027/uiug. 30112045346175 ? urlappend $=\% 3$ Bseq $=33$ [fecha de consulta: 15 de mayo de 2020]. 
las prioridades de las estaciones, por lo que se capacitaron extensionistas en el terreno y se enviaron a otros a formarse en Estados Unidos ${ }^{111}$. Por ejemplo, luego de la visita de Dorothy Chapman, dos técnicos de Tingo María fueron enviados a Estados Unidos para formarse en organización y métodos de extensión agrícola, mientras que otros dos viajaron para especializarse en horticultura y fisiología de plantas y en patología de plantas ${ }^{112}$. En 1946, la inauguración de los cursos del Instituto Interamericano de Ciencias Agrícolas en Costa Rica abriría nuevas oportunidades para la formación de agrónomos de áreas tropicales en investigación y extensión.

Esto pone de relieve que, además de la confianza en las capacidades de la agricultura científica, los expertos habían iniciado el programa con la certeza de que era posible transformar el escenario rural latinoamericano.

\section{EL POTENCIAL DE LA AGRICULTURA CIENTÍFICA: \\ OPTIMISMO, INCERTIDUMBRE Y CLAUSURA}

Los primeros años del programa se caracterizaron por un clima de optimismo que se iría diluyendo con el tiempo. En 1941, E. W. Brandes afirmaba:

"La enfermedad no presenta ningún problema, nuevo o extraño, a biólogos competentes acostumbrados a afrontar problemas similares en otros cultivos. Para atacar el problema de esta enfermedad hay no menos de cinco caminos a seguir: (1) usar cepas de Hevea resistente ahora disponibles; (2) testear y seleccionar o cruzar otras más resistentes; (3) plantar en áreas todavía libres de la enfermedad, donde es posible que haya un retraso en la invasión de la enfermedad; (4) plantar en ambientes donde las condiciones naturales son desfavorables para la epidemia; (5) aplicar medidas de control directo, como espolvorear y rociar [con fungicidas], especialmente en los viveros, donde las plantas jóvenes son más susceptibles al daño. El científico no está atemorizado por ningún aspecto de esta enfermedad y no hay motivo para que el plantador se alarme injustificadamente. El problema se resuelve con solo otro trabajo de la agricultura científica" $" 13$.

Sin embargo, en el trópico, el problema no era tan sencillo. Uno de los primeros estudios comparativos realizado por Michael H. Langford en Turrialba y Carl Butler en el IAN, que involucró plántulas de Hevea brasiliensis de Belém y clones filipinos, mostró variaciones pronunciadas en la virulencia entre ambas localidades ${ }^{114}$. El carácter pronunciado de las variaciones complejizó un poco más el programa, pues puso en evidencia la necesidad de evaluar la susceptibilidad de las selecciones o híbridos en diversas localidades/ambientes de América Latina ${ }^{115}$. A mediados de la década de 1940 los

\footnotetext{
${ }^{111}$ Cuvi, "Las semillas...", op. cit.

${ }^{112}$ Moore, "Agricultural Cooperation...", op. cit.

${ }^{113}$ Brandes, "Rubber on the...", op. cit., p. 6.

${ }^{114}$ Semillas de la región de Belém también fueron enviadas a Haití, Honduras y otros siete países para compararlas con plantas de semillas locales. USDA, "Memorandum for Employees of Rubber Plant Investigations, Progress Report N 9...”, op. cit.

${ }^{115}$ Rands \& Polhamus, op. cit., pp. 10-11.
} 
estudios comparados entre Costa Rica y Perú pusieron de relieve que, si hasta entonces se había prestado atención a la incidencia de factores ambientales en la virulencia del hongo, también era posible imaginar que las variaciones se debieran a la presencia de diversas cepas del hongo. Esto fue confirmado poco después de finalizar la guerra, con la identificación de, al menos, dos cepas ${ }^{116}$. Peor aún, entre 1944 y 1945, un rebrote de la enfermedad en Brasil reveló que algunas selecciones resistentes eran susceptibles ${ }^{117}$. A partir de 1945, la lista de selecciones comenzó a modificarse ${ }^{118}$.

Dos factores adicionales generaron incertidumbre sobre la viabilidad del programa. En primer lugar, la epidemia afectó viveros situados en ambientes supuestamente menos favorables para la difusión de la enfermedad e, incluso, en ambientes que se creían libres de la enfermedad (como Honduras, Guatemala y México). En segundo lugar, la aparición de nuevas enfermedades, como el target leaf spot, causado por el hongo pellicularia filamentosa, resultó un nuevo escollo a sortear. Este hongo fue detectado por primera vez en 1941 en Lancetilla (Honduras) y en Belém (Brasil) y, un año más tarde, también se detectó en Tingo María e Iquitos (Perú). Entre 1944 y 1945 la enfermedad adquirió proporciones epidémicas en los viveros y plantaciones de Perú, afectando tanto los clones susceptibles como los resistentes, por lo que se destinó un patólogo del USDA para controlar la enfermedad y probar clones resistentes del IAN. En 1946 y 1947 la enfermedad fue detectada en Colombia y Costa Rica, respectivamente ${ }^{119}$, por lo que, en principio, algunos países requerirían árboles con resistencia a más de una enfermedad.

Asimismo, la primera generación de cruces entre clones resistentes -seleccionados por Ford-y clones orientales - realizada bajo la dirección de Charles H. Townsend en Brasil- se reveló muy improductiva y condujo a sucesivos retrocruzamientos con clones orientales. Sin embargo, cuando finalizó el programa no se sabía aún si la resistencia se mantendría a través de dichos retrocruzamientos. Años más tarde, luego de testar la tercera generación de retrocruzamientos, comenzó a asumirse que la resistencia dependía de diversos genes y no podía mantenerse a lo largo de los retrocruzamientos ${ }^{120}$.

A principios de la década de 1950 los expertos del USDA no habían logrado obtener un híbrido lo suficientemente resistente y con rendimiento equivalente a los mejores clones asiáticos ${ }^{121}$. Tampoco se habían realizado avances significativos en la difusión de la Hevea entre pequeños productores ${ }^{122}$. Terminada la guerra, ante el nuevo escenario del mercado cauchero, Ecuador, Venezuela, Nicaragua, El Salvador, Honduras y Panamá dejaron de participar en el proyecto. En el resto de los países, algunos de los

\footnotetext{
${ }^{116}$ Michael H. Langford, "South American Leaf Blight of Hevea Rubbertrees", in USDA Technical Bulletin, No. 882, Washington D.C., 1945. Rands \& Polhamus, op. cit., p. 66.

${ }^{117}$ Dean, op. cit., p. 97.

${ }^{118}$ Rands \& Polhamus, op. cit., pp. 10 \& 20.

119 John B. Carpenter, "Target Leaf Spot on the Hevea Rubbertree in Relation to Host Development, Infection, Defoliation, and Control”, in USDA Technical Bulletin, No. 1028, Washington D.C., 1951; Rands \& Polhamus, op. cit., p. 67.

${ }^{120}$ Clément-Demange, Priyadarshan, Hoa \& Venkatachalan, op. cit., p. 208.

${ }^{121}$ Rands \& Polhamus, op. cit., p. 73.

${ }^{122}$ R. D. Rands \& William Mackinnon, "Small-farm Rubber Production in Latin America", in Foreign Agriculture, vol. XIV, No. 3, Washington D.C., 1950, pp. 64-67.
} 
factores aquí descritos, sumados a las dificultosas -y no siempre exitosas- operaciones de injerto y los tiempos requeridos para evaluar la productividad limitaron el desarrollo del programa.

Con todo, a fines de la década de 1940 los expertos del USDA y de Goodyear creían que el programa era viable e, incluso, deseable ${ }^{123}$. Sin embargo, en octubre de 1953 el programa fue cancelado, lo que implicó el cierre del centro de Turrialba y el retiro de todos sus archivos. Wade Davis relata que "En menos de un año [funcionarios del Departamento de Estado] talaron casi todos los cauchos de Turrialba y Los Diamantes. El semillero de clones que había sido depósito genético de todo el continente fue reemplazado por un sembradero de caña de azúcar"124. Según Richard Tucker, el motivo fue que los trabajadores de Turrialba estaban comprometidos con el Frente Popular, al que el Departamento de Estado consideraba filocomunista ${ }^{125}$.

\section{CONCLUSIONES}

Las exploraciones realizadas por el USDC, la creación de los Summit Gardens, las plantaciones experimentales de la UFCo y el emprendimiento de Ford en Brasil coincidieron en la década de 1920, poniendo de relieve que las élites políticas y económicas de Estados Unidos compartieron con otras potencias imperiales el sueño de una naturaleza tropical gestionada sobre bases "racionales", es decir, científicas ${ }^{126}$. La Segunda Guerra Mundial marcó un viraje en el tipo de estrategias desplegadas para concretar ese sueño, situando al Estado como actor protagónico -aunque no único- en la construcción de la ciencia occidental como ciencia universal y, a su vez, como herramienta para la articulación de una economía hemisférica. Sin embargo, mientras que el cultivo de Hevea en las Indias Holandesas, Malasia e Indochina se instituyó en un caso exitoso de dominio tecnocientífico sobre la naturaleza y de complementariedad productiva ${ }^{127}$, el programa de Estados Unidos en América Latina solo puede considerarse como una más de las utopías de integración interamericana, en las que confluían los principios de la política exterior, el expansionismo comercial y la empresa científica ${ }^{128}$. Pese a eso, el caso aquí presentado es un terreno fértil para reflexionar sobre las relaciones tecnocientíficas entre Estados Unidos y América Latina.

En la introducción señalé que la conceptualización de las relaciones tecnocientíficas Norte-Sur es problemática, que el concepto de cooperación científica se ha utilizado para hacer referencia a prácticas muy distintas $\mathrm{y}$, con probabilidad, presente dificultades

\footnotetext{
${ }^{123}$ Bangham, op. cit.

${ }^{124}$ Davis, op. cit., p. 679.

125 Tucker, op. cit., p. 279.

${ }^{126}$ Bonneuil, op. cit.

${ }^{127}$ Worboys, op. cit.; Bonneuil, op. cit.

${ }^{128}$ Ricardo D. Salvatore, "Imperial Mechanics: South America's Hemispheric Integration in the Machine Age", in American Quarterly, vol. 58, No. 3, Baltimore, 2006, pp. 662-691. El autor hace referencia a la construcción de imaginarios de integración hemisférica a partir de proyectos de conexión territorial o "utopías de transporte" (vía férrea, autopista, líneas aéreas), concebidos en las primeras cuatro décadas del siglo XX y que no alcanzaron a concretarse en plenitud.
} 
para aplicarlo al caso analizado o a otros casos correspondientes al mismo periodo. Aunque las propuestas de conceptualización y periodización de largo plazo de las relaciones tecnocientíficas Norte-Sur no han contemplado casos similares al que aquí presenté, ofrecen claves interpretativas interesantes para analizarlo.

Por ejemplo, Pablo Kreimer propuso hace tiempo el concepto de "integración subordinada" para definir una modalidad de relaciones tecnocientíficas entre centros y periferias -específicamente América Latina- que se inicia en la década de 1960 y se extiende hasta los más recientes Programas Marco de la Unión Europea. Lo característico de dicha modalidad es la restricción de los márgenes de negociación de las agendas de cooperación por parte de los países en desarrollo, así como la participación de sus grupos de investigación en el diseño de los proyectos. En ese marco, "los grupos localizados en países periféricos tienden a realizar actividades de un alto contenido y especialización técnica, pero que son subsidiarias de problemas científicos y/o productivos ya definidos previamente" 129 .

No obstante, es posible que el valor heurístico del concepto tenga menos que ver con la definición de periodos específicos que con arreglos institucionales que atraviesan distintas etapas y suponen el involucramiento de los Estados, instituciones y científicos "del Norte" en el diseño de programas de investigación a gran escala orientados a objetivos preestablecidos. De hecho, el programa de cultivo de Hevea en América Latina -y de cultivos estratégicos en general- tiene varios elementos que permitirían inscribirlo, grosso modo, dentro de esa dinámica de "integración subordinada", aunque con algunas especificidades. Como vimos, se trató de un proyecto a gran escala, diseñado de manera conjunta por el BPI y las grandes corporaciones estadounidenses, que asignaron un papel específico a cada país, a cada institución y, por lo tanto, a cada actor en el programa general. El acceso privilegiado al territorio latinoamericano, a la información derivada del mapeamiento de especies y variedades, al historial de cruzamientos, a las evaluaciones realizadas en los diversos centros colaboradores se combinó, además, con la capacidad de explotar comercialmente esa información en caso de que la investigación llegara a buen puerto. Desde luego, dado que América Latina es una región bastante heterogénea, existen grados de subordinación -y de autonomía-, que dependen de la capacidad -científica, política y económica- de cada país o élite científica para negociar sus condiciones o participar en el diseño de la investigación. Aquí he propuesto un enfoque a escala regional que deja abiertos muchos interrogantes acerca de las especificidades nacionales -en términos de procesos de cooperación, resistencia, negociación etc.- y que pueden ser objeto de nuevas investigaciones.

Ahora bien, cuando se toman en consideración algunas especificidades del periodo analizado, de los arreglos institucionales a partir de los cuales se organizó el programa y del tipo de interlocutores y conocimiento involucrados, el concepto de "integración su-

${ }^{129}$ Kreimer, op. cit., p. 209; Adriana Feld \& Pablo Kreimer, "Cosmopolitanism or subordination? Latin American scientists' participation in European programs: motivations and dynamics analyzed from the European scientific leaders' point of view", in História, Ciências, Saúde-Manguinhos, vol. 26, n. ${ }^{\circ}$ 3, Rio de Janeiro, 2019, pp. 779-799. Disponible en http://www.scielo.br/scielo.php?script=sci_arttext\&pid=S010459702019000300779\&lng=en\&nrm=iso [fecha de consulta: 4 de diciembre de 2020]. 
bordinada" puede pensarse como una clasificación general con distintas declinaciones. En primer lugar, los programas agrícolas del periodo de guerra e inmediata posguerra se organizaron sobre la base de una serie de acuerdos intergubernamentales, interpelando tanto a las élites políticas y económicas como a los cuadros técnicos ministeriales y a la población rural. Eso implicó - a diferencia de lo que sucede con otros dispositivos de cooperación científico-técnica- el despliegue de múltiples estrategias diplomáticas, que abarcaban desde la diplomacia del dólar (los créditos) y la diplomacia tradicional (acuerdos bilaterales o agregados agrícolas en las embajadas) hasta la diplomacia cultural (programas educativos) y dispositivos híbridos entre estas dos últimas (como el Octavo Congreso Científico Americano).

En segundo lugar, las estaciones dirigidas, y en ocasiones financiadas, por el USDA - como en el caso de Costa Rica o Haití- o la presencia relativamente estable de botánicos, patólogos, genetistas y agrónomos estadounidenses en dichas estaciones, permitirían hablar de una "integración subordinada" a través de "enclaves científicos", similares a los "enclaves tecno-burocráticos" establecidos por el IIAA en los ministerios de agricultura ${ }^{130}$. Aunque las metrópolis europeas también habían creado enclaves de investigación agrícola en sus colonias, como el Institut de Recherches sur le Caoutchouc de Indochina (1940), ligado al Institut Français du Caoutchouc (1936), los enclaves latinoamericanos se insertaban en un contexto y un entramado institucional diferente. En el caso de Francia, por ejemplo, las actividades de investigación eran llevadas a cabo por científicos o técnicos de las metrópolis ${ }^{131}$. Por el contrario, muchos países de América Latina contaban ya con cuadros técnicos e instituciones de formación que, en todo caso, era necesario -desde la perspectiva del "Norte"- reorientar, reformar o especializar a través de estadías en Estados Unidos, de la formación en el terreno o de la creación de instituciones como el IICA ${ }^{132}$.

En ese sentido, los programas del USDA y el IIAA contenían el germen de dos de los mecanismos de internacionalización de la tecnociencia más propios del periodo de posguerra. El primero de ellos es la transferencia de conocimientos, que fue el leit motiv de los programas diseñados bajo el paraguas del Punto IV. En efecto, los discursos y, en ocasiones, las prácticas de agencias como el USDA y el IIAA estaban atravesadas por la profunda confianza en la capacidad de la agricultura "científica" estadounidense para transformar el escenario rural latinoamericano, transfiriendo conocimiento científico - embebido en variedades productivas y resistentes, fungicidas, fertilizantes y hasta ma-

${ }^{130}$ Picado y Fernández, op. cit., refieren a una "clonación de instituciones" creadas en diversos países de América Latina por el IIAA.

131 Jacques Gaillard \& Lawrence Busch, "French and American Agricultural Science for the Third World", in Science and Public Policy, vol. 20, No. 4, Oxford, 1993, pp. 222-234; Christophe Bonneuil \& Patrick Petitjean, "Science and French Colonial Policy: Creation of the ORSTOM from the Popular Front to the Liberation via Vichy, 1936-1947”, in Terry Shinn, Jack Spaapen \& Venni Krishna (dirs.), Science and Technology in a Developing World, Dordrecht, Kluwer Academic Publishers, 1997, pp. 129-178. El Institut de Recherches sur le Caoutchouc de Indochina se creó con fondos provenientes de las plantaciones, siguiendo el modelo de instituciones como el AVROS de Indonesia y el Rubber Research Institute de Malasia. IRCA, Institut de Recherches sur le Caoutchouc. Historique, 1990. Disponible en https://agritrop.cirad.fr/584863/1/ ID584863.pdf [fecha de consulta: 4 de diciembre de 2020].

${ }^{132}$ Rands \& Polhamus, op. cit., p. 3. 
quinaria-, tecnológico - encarnado en la maquinaria- y técnico - manejo de los suelos, técnicas de cultivo- a los cuadros técnicos latinoamericanos, encargados de difundirlo -vía extensión- a los productores. En 1947, un funcionario de la OFAR destacaba ese objetivo como eje de los programas de cultivos complementarios:

“[...] un incremento en la eficiencia de la producción y la distribución puede lograrse mejor mediante la máxima reutilización de la experiencia técnica a través de la transferencia de conocimiento científico aplicable y de capacidades desde lugares donde están más desarrolladas hacia áreas en las que puede ser efectivamente aplicado. La cooperación entre los países, por lo tanto, debe ser de tal naturaleza que facilite la pronta transferencia y adaptación de dichas experiencias" $" 133$.

La transferencia de conocimiento, a su vez, se enlazaba con el segundo mecanismo: la difusión de modelos institucionales. Por ejemplo, el texto de Deborah Fitzgerald sobre el Proyecto Agrícola Mexicano iniciado por la Fundación Rockefeller en 1943 pone de relieve que el proyecto se organizó tomando como referencia el modelo institucional estadounidense de los land-grant colleges, en los que se articulaban la educación superior, las estaciones experimentales y la extensión ${ }^{134}$. Su trabajo muestra que la difusión de prácticas de investigación (como la selección de variedades superiores o la producción de híbridos) puede formar parte de un paquete mucho más amplio de conocimientos de distinto orden destinados a diversos actores. En ese sentido, el know-how de organización y gestión, basado en el modelo institucional estadounidense, se orientó a los cuadros técnicos ministeriales y a las élites organizacionales académicas. Como vimos, esa idea también comenzaba a resonar, quizá con menos vigor, en los programas educativos de instituciones como el USDA y del IIAA. Concebida de manera incipiente en la década de 1940, la transferencia de modelos institucionales será el objetivo primordial de la asistencia provista por Estados Unidos a las universidades latinoamericanas en la década de 1960, aunque esta vez a una escala mayor y bajo el lema de la "construcción institucional" in situ ${ }^{135}$. Aun así, la idea fuerza que subyace a los programas diseñados durante la guerra y la inmediata posguerra, no es la generación de capacidades de investigación en sentido amplio, sino la aculturación de cuadros técnicos en las diversas dimensiones (institucionales, productivas, técnicas y científicas) del "paquete tecnocientífico" estadounidense. La inserción de dichos cuadros en "redes de conocimiento" internacionales a partir de su formación en Estados Unidos o de la interacción local con científicos y expertos extranjeros fue el principal mecanismo de aculturación ${ }^{136}$.

\footnotetext{
${ }^{133}$ Moore, op. cit., p. 7.

${ }^{134}$ Deborah Fitzgerald, "Exporting American Agriculture. The Rockefeller Foundation in México, 19431953”, in Cueto, op. cit., pp. 72-96.

${ }^{135}$ Daniel Levy, To export progress. The golden age of university assistance in the Americas, Bloomington, Indiana University Press, 2005; Gaillard, op. cit.

${ }^{136}$ Nicolás Cuvi señala que estos "agrobraceros" formados en la "nueva agricultura científica" e insertos en redes internacionales ocuparon puestos claves en sus propios países, contribuyendo a implementar la Revolución Verde. Cuvi, "Expertos, Agrobraceros...", op. cit.
} 